Regular Article

Fighlighted Laper selected by Bditor-in-Ghief

\title{
Design, Synthesis and Biological Evaluation of Novel Nonsteroidal Progesterone Receptor Antagonists Based on Phenylamino-1,3,5-triazine Scaffold
}

\author{
Kazuma Kaitoh, ${ }^{a}$ Aki Nakatsu, ${ }^{b}$ Shuichi Mori, ${ }^{b}$ Hiroyuki Kagechika, ${ }^{b}$ Yuichi Hashimoto, ${ }^{a}$ and \\ Shinya Fujii*,a,b \\ ${ }^{a}$ Institute for Quantitative Biosciences, The University of Tokyo; 1-1-1 Yayoi, Bunkyo-ku, Tokyo 113-0032, \\ Japan: and ${ }^{b}$ Institute of Biomaterials and Bioengineering, Tokyo Medical and Dental University; 2-3-10 Kanda- \\ Surugadai, Chiyoda-ku, Tokyo 101-0062, Japan. \\ Received February 4, 2019; accepted February 25, 2019
}

\begin{abstract}
We report here the development of phenylamino-1,3,5-triazine derivatives as novel nonsteroidal progesterone receptor (PR) antagonists. PR plays key roles in various physiological systems, including the female reproductive system, and $P R$ antagonists are promising candidates for clinical treatment of multiple diseases. By using the phenylamino-1,3,5-triazine scaffold as a template structure, we designed and synthesized a series of 4-cyanophenylamino-1,3,5-triazine derivatives. The synthesized compounds exhibited PR antagonistic activity, and among them, compound $12 \mathrm{n}$ was the most potent $\left(\mathrm{IC}_{50}=0.30 \mu \mathrm{M}\right)$; it also showed significant binding affinity to the PR ligand-binding domain. Docking simulation supported the design rationale of the compounds. Our results suggest that the phenylamino-1,3,5-triazine scaffold is a versatile template for development of nonsteroidal PR antagonists and that the developed compounds are promising lead compounds for further structural development of nonsteroidal PR antagonists.
\end{abstract}

Key words progesterone receptor; antagonist; multi-template; triazine

\section{Introduction}

Progesterone receptor (PR) is a member of the nuclear receptor superfamily of ligand-dependent transcription factors. ${ }^{1)}$ PR is expressed in female tissues including uterus, ovary and breast, and plays essential roles in female reproductive systems, being associated with the establishment and maintenance of pregnancy and with alveolar development in the breast. ${ }^{2,3}$ Recent studies suggest that PR also has a role in the central nervous system. ${ }^{4-6)}$ PR agonists, including the endogenous agonist progesterone (1), have been used extensively to treat gynecological disorders, as well as in female contraception and hormone replacement therapy. ${ }^{7-9)}$ Among nonsteroidal PR agonists, the investigational compound tanaproget (2) seems to be the most promising compound for clinical use. ${ }^{10,11)}$ In addition, PR antagonists are potentially useful for the treatment of various diseases, including hormone-dependent cancers, ${ }^{12,13)}$ uterine fibroids, ${ }^{14)}$ and endometriosis, ${ }^{15)}$ and also as abortifacients. The steroidal compound mifepristone (3) is the most intensively investigated PR antagonist, ${ }^{16)}$ but has found only limited clinical use as an abortifacient so far. Therefore, to assess the potential clinical utility of this class of compounds, further development, especially of potent nonsteroidal PR antagonists, is needed. Based on the structure of the nonsteroidal PR agonist 2, several nonsteroidal PR antagonists, such as $\mathbf{4}$ and $\mathbf{5}$, have been developed. ${ }^{17-19)}$ In addition to these tanaproget derivatives, nonsteroidal PR antagonists with novel chemotypes distinct from tanaproget (2) have been also investigated. For example, 3-aryl indole derivatives including 6 were developed as PR antagonists to treat uterine fibroids, ${ }^{20)}$ and other structures such as $\mathbf{7}$ and $\mathbf{8}$ have also been reported in recent years ${ }^{21-24)}$ (Fig. 1). In short, novel types of nonsteroidal PR antagonists are of interest as potential drug candidates.
In this paper, we report the design and synthesis of a series of 2-(4-cyanophenylamino)-4-phenoxy-1,3,5-triazine derivatives as novel PR antagonists.

\section{Results and Discussion}

Chemistry In this work, we applied the multi-template approach. This is based on the fact that the number of three-dimensional spatial structures (fold structures) of human proteins is only approximately 1000, which is much smaller than the number of human proteins, estimated to be 50000-70000. ${ }^{25,26)}$ Therefore, compounds binding to a particular fold structure are likely to serve as ligands for multiple proteins. We have previously employed multi-template structures such as thalidomide ${ }^{27)}$ and diphenyl-X (Ph-X-Ph) as represented by diphenylmethane ${ }^{28)}$ to obtain various bioactive compounds. Recently, we also demonstrated that the phenylamino-1,3,5-triazine scaffold is a useful core structure for development of nuclear receptor modulators, enabling facile structure-activity relationship (SAR) investigation, and we developed novel inverse agonists of nuclear retinoic acid receptor-related orphan receptor- $\gamma(\operatorname{ROR} \gamma){ }^{29)}$ In the phenylamino-1,3,5-triazine scaffold, the diarylamine is a diphenyl-X homolog and is an established multi-template for nuclear receptor ligands. Further, the 4- and 6-positions of 1,3,5-triazine are available as points of systematic structural modification. In view of these advantages, we chose this scaffold to develop novel PR antagonists.

First, we designed the 2-(4-cyanophenylamino)-4-phenoxy1,3,5-triazine derivatives shown in Fig. 2. The known nonsteroidal PR antagonists illustrated in Fig. 1 suggested that the cyanoaryl moiety is an important pharmacophore for PR-modulating activity, and therefore we chose the 4-cyano 
<smiles>CC(=O)C1CCC2C3CCC4=CC(=O)CCC4(C)C3CCC12C</smiles><smiles>CC#CC1(O)CCC2C3CCC4=CC(=O)CCC4=C3C(c3ccc(N(C)C)cc3)CC21C</smiles>

Mifepristone (RU486: 3) antagonist<smiles>Cn1c(C#N)ccc1-c1ccc2c(c1)C(C)(C)OC(=S)N2</smiles>

Tanaproget (2) agonist<smiles>CC(C)n1cc(-c2ccc(C#N)c(F)c2)c2ccc(NS(C)(=O)=O)cc21</smiles>

6

antagonist<smiles>CC1(C)OC(=O)Nc2ccc(-c3ccc(C#N)s3)cc21</smiles>

4 antagonist<smiles>O=S(=O)(Nc1cccc(C(F)(F)F)c1)c1ccc(Oc2ccccc2)cc1</smiles>

7

antagonist<smiles>Cn1c(C#N)ccc1-c1ccc2oc(=O)ccc2c1</smiles>

5

antagonist<smiles>Cc1cc(C(O)(C(F)(F)F)C(F)(F)F)cc2c3ccc(F)cc3c(=O)n(C)c12</smiles>

8

antagonist

Fig. 1. Structures of Representative Steroidal and Nonsteroidal PR Ligands

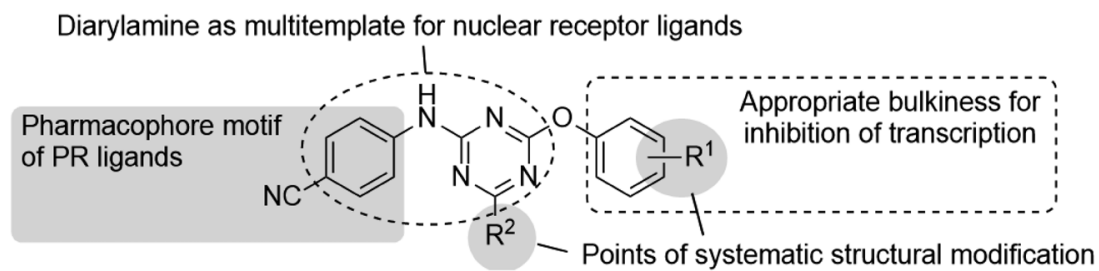

Fig. 2. Design Scheme for Novel PR Antagonists Based on the Phenylamino-1,3,5-triazine Scaffold as a Template<smiles>Clc1nc(Cl)nc(Cl)n1</smiles>

cyanuric chloride (9)<smiles>COc1nc(Cl)nc(Cl)n1</smiles>

10<smiles>[R]c1ccc(Oc2nc(Cl)nc(OC)n2)cc1</smiles>

11a-p

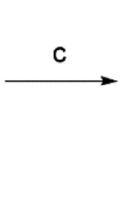
e : $\mathrm{R}^{1}=2-\mathrm{CF}_{3}$
f: $\mathrm{R}^{1}=3-\mathrm{CF}_{3}$
g: $\mathrm{R}^{1}=4-\mathrm{CF}_{3}$
h: $R^{1}=2-F$
$i: R^{1}=3-F$
$\mathrm{j}: \mathrm{R}^{1}=4-\mathrm{F}$

b : $\mathrm{R}^{1}=2-\mathrm{Me}$

d : $\mathrm{R}^{1}=4-\mathrm{Me}$<smiles>[R][X]1ccc(Oc2nc(Nc3ccc(C#N)cc3)nc(OC)n2)cc1</smiles>

$k: R^{1}=2-C O M e$

I : $\mathrm{R}^{1}=3$-COMe

m: $R^{1}=4-C O M e$

$n: R^{1}=2-O M e$

o: $\mathrm{R}^{1}=3-\mathrm{OMe}$

p : $R^{1}=4-O M e$

Reagents and conditions: (a) $\mathrm{NaHCO}_{3}, \mathrm{MeOH}, 0^{\circ} \mathrm{C}, 74 \%$; (b) $\mathrm{R}^{1}-\mathrm{C}_{6} \mathrm{H}_{4}-\mathrm{OH}, i-\mathrm{Pr}_{2} \mathrm{EtN}, \mathrm{CH}_{2} \mathrm{Cl}_{2}$, r.t., $34-79 \%$; (c) $4-\mathrm{CN}-\mathrm{C}_{6} \mathrm{H}_{4}-\mathrm{NH}_{2}, i-\mathrm{Pr}_{2} \mathrm{EtN}$, reflux in $\mathrm{THF}$ or $100{ }^{\circ} \mathrm{C}$ in DMSO, 8-60\%.

Chart 1. Synthesis of the Designed Triazine Derivatives $\mathbf{1 2 a}-\mathbf{p}$

group as the substituent on the phenylamino group. In order to exert inhibitory activity toward nuclear receptors, antagonists must be sufficiently bulky to induce the inactive conformation of the receptors. ${ }^{30)}$ Our previous results indicated that the phenoxy group is large enough for this purpose. ${ }^{29)}$ Further, as substituents on the phenoxy and the triazine moiety, we chose a set of substituents present in previously developed PR ligands, such as fluoro, methyl, trifluoromethyl, isopropyl, acetyl, and dimethylamino groups (Fig. 2).

The designed compounds were synthesized in three steps as illustrated in Charts 1 and 2. Synthesis of methoxytriazine derivatives bearing various substituents at the phenoxy group $\mathbf{1 2 a}-\mathbf{p}$ is summarized in Chart 1. The methoxy group, phenoxy group and 4-cyanophenylamino group were successively connected by means of sequential nucleophilic substitutions (Chart 1). The derivatives $\mathbf{1 5 a}-\mathbf{g}$ bearing various alkoxy groups and compounds $\mathbf{1 7} \mathbf{a}$ and $\mathbf{1 7} \mathbf{b}$ bearing amino groups at the triazine ring were similarly synthesized by means of sequential nucleophilic substitutions (Chart 2).

Biological Activity The PR-agonistic and -antagonistic activities of synthesized triazine derivatives were evaluated by means of alkaline phosphatase assay using T47D human breast carcinoma cell line. ${ }^{31)}$ None of the triazine derivatives examined induced alkaline phosphatase activity alone (data not shown), i.e., they did not possess PR-agonistic activity. PR-antagonistic activity was examined in terms of the activity of the test compounds in the presence of $1 \mathrm{nM}$ progesterone (1) (Table 1).

All the synthesized triazine derivatives exhibited PRantagonistic activity with the exception of $\mathbf{1 2} \mathbf{~ m}$. In the case of tanaproget (2)-based PR ligands such as 4, quite small structural modifications can alter the activity, including agonist/an- 


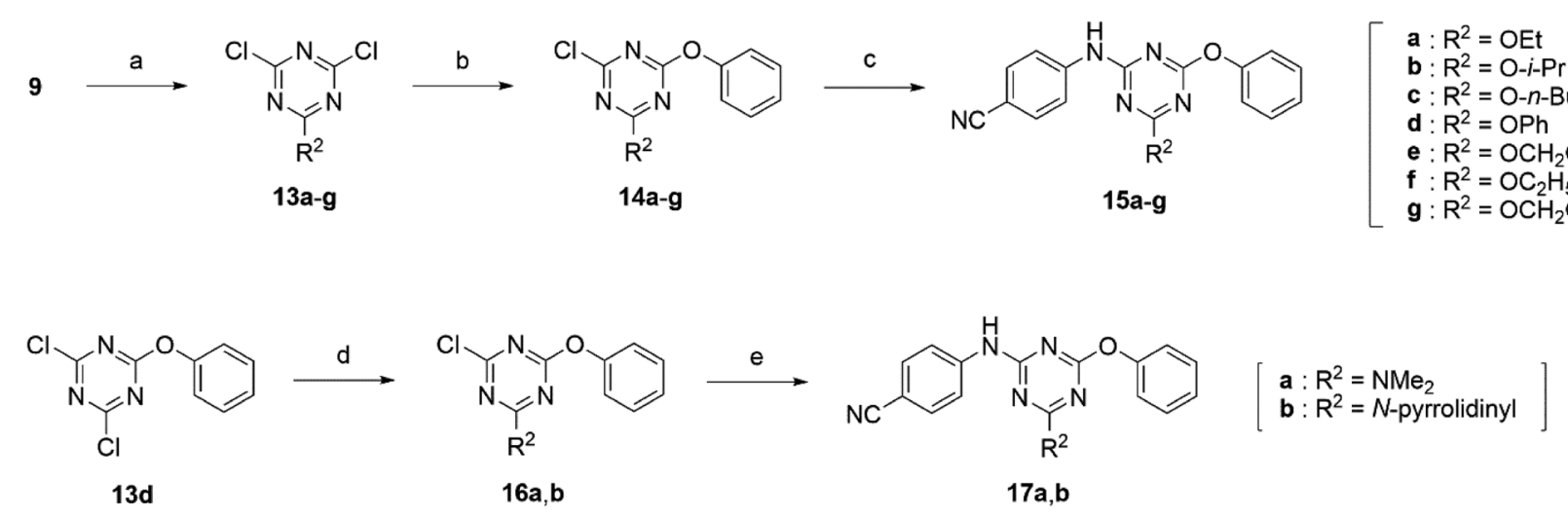

Reagents and conditions: (a) $\mathrm{R}^{2}-\mathrm{H}, \mathrm{NaHCO}_{3}$, (for 13a and 13b), or $\mathrm{R}^{2}-\mathrm{H}, i-\mathrm{Pr}_{2} \mathrm{EtN}, \mathrm{CHCl}_{3}, 0^{\circ} \mathrm{C}, 34-64 \%$; (b) phenol, $i-\mathrm{Pr}_{2} \mathrm{EtN}, \mathrm{CH}_{2} \mathrm{Cl}_{2}, \mathrm{r} . \mathrm{t}$., $62-84 \%$; (c) $4-\mathrm{CN}_{-} \mathrm{C}_{6} \mathrm{H}_{4}-\mathrm{NH}_{2}$, $i$-Pr $\mathrm{EtN}_{2}$ DMSO, $100^{\circ} \mathrm{C}, 23-87 \%$; (d) $\mathrm{Me}_{2} \mathrm{NH}$ or pyrrolidine, $i-\mathrm{Pr}_{2} \mathrm{EtN}, \mathrm{THF}_{2}$, r.t., $67 \%(\mathbf{1 6 a}), 86 \%(\mathbf{1 6 b}) ;(\mathrm{e}) 4-\mathrm{CN}-\mathrm{C}_{6} \mathrm{H}_{4}-\mathrm{NH}_{2}, i-\mathrm{Pr}_{2} \mathrm{EtN}, \mathrm{DMSO}, 160^{\circ} \mathrm{C}, 33 \%(\mathbf{1 7 a}), 44 \%$ (17b).

Chart 2. Synthesis of the Designed Triazine Derivatives $\mathbf{1 5 a}-\mathbf{g}$ and $\mathbf{1 7 a}, \mathbf{b}$

Table 1. PR-Antagonistic Activity of Triazine Derivatives in Alkaline Phosphatase Assay

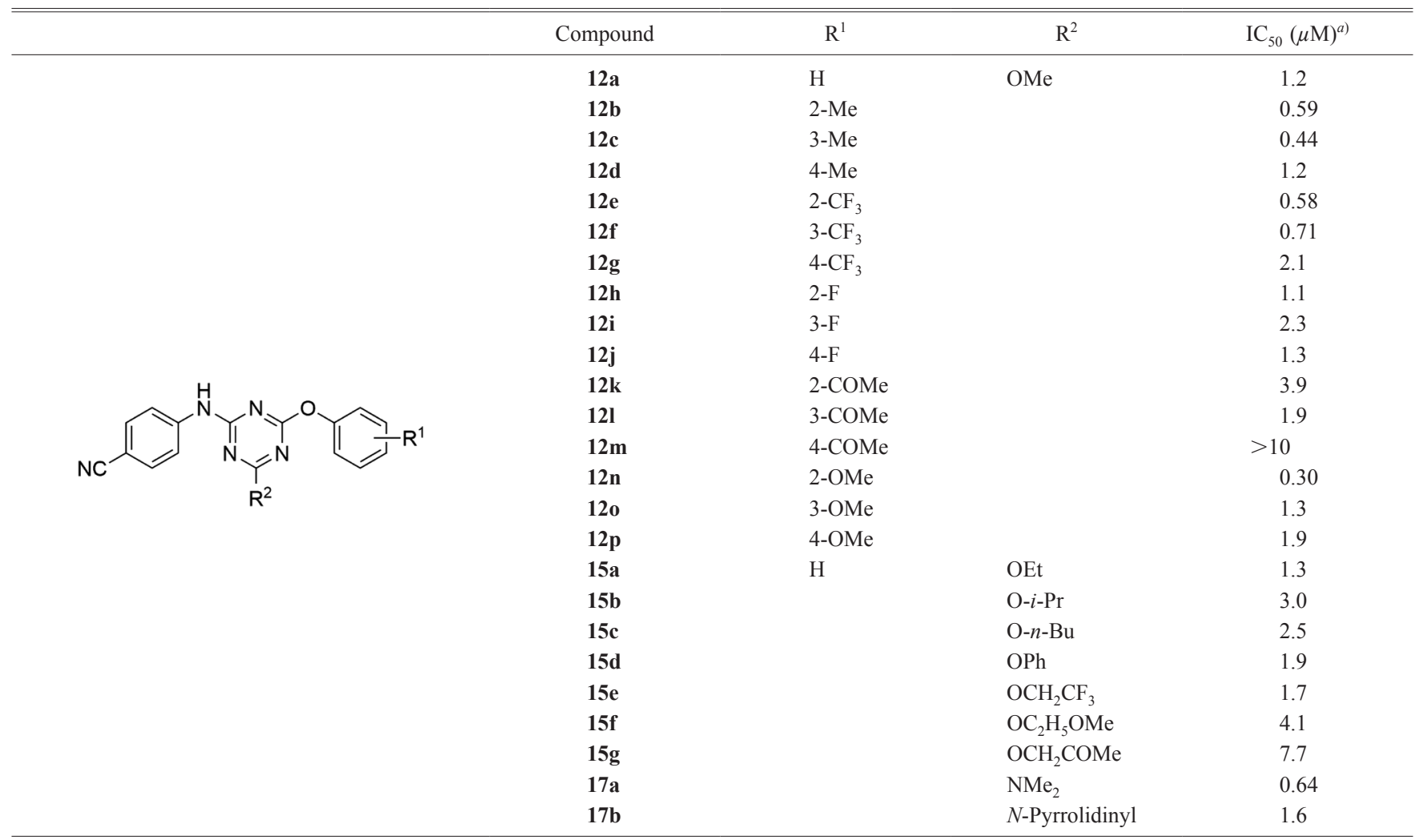

a) Expression of alkaline phosphatase was induced with $1 \mathrm{nM}$ progesterone.

tagonist activity switching. ${ }^{17,18)}$ The results suggested that the 2-(4-cyanophenylamino)-4-phenoxy-1,3,5-triazine structure is favorable for PR-antagonistic activity. Compound 12a exhibited significant PR-antagonistic activity with an $\mathrm{IC}_{50}$ value of $1.2 \mu \mathrm{M}$. Introduction of a methyl group at the 2- or 3-position of the phenoxy moiety (12b and 12c) enhanced the PR-antagonistic potency, whereas introduction at the 4-position did not (12d). The effect of introduction of a trifluoromethyl group $(\mathbf{1 2} \mathbf{e}-\mathbf{g})$ was similar to that of a methyl group, and introduction of a fluoro group $(\mathbf{1 2 h}-\mathbf{j})$ or an acetyl group $(\mathbf{1 2} \mathbf{k}-\mathbf{m})$ reduced the potency. The 2-position of the phenoxy group seems favorable for substitution, and 2-methoxyphenoxy derivative 12n exhibited the most potent activity among the examined compounds, with an $\mathrm{IC}_{50}$ value of $0.30 \mu \mathrm{M}$. Regarding the substituent at the triazine ring $\left(\mathrm{R}^{2}\right.$ in Table 1$)$, elongation or enlargement of the alkoxy group reduced the PR-antagonistic potency $(\mathbf{1 5 a}-\mathbf{g})$. Amino-substitution at the triazine ring was acceptable, and dimethylamino derivative 17a exhibited potent activity with an $\mathrm{IC}_{50}$ value of $0.64 \mu \mathrm{M}$.

Next the binding affinity of selected compounds was examined by competitive binding assay using ${ }^{3} \mathrm{H}$-labelled progesterone ([$\left.\left.{ }^{3} \mathrm{H}\right]-\mathrm{P} 4\right)$ and human $\mathrm{PR}$ ligand-binding domain (LBD) (Fig. 3). Compounds 12n and 17a, which showed potent PR-antagonistic activity in alkaline phosphatase assay, exhibited dose-dependent binding to PR LBD. Although their binding potency was lower than that of steroidal PR antagonist 


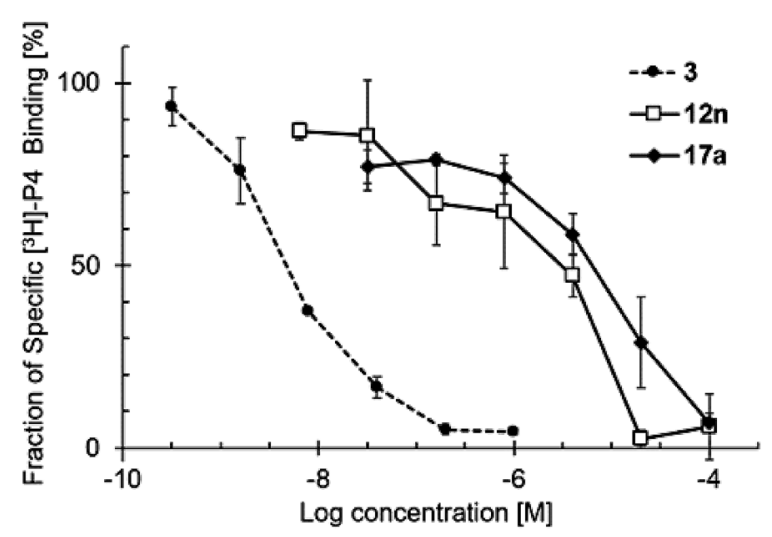

Fig. 3. Competitive Binding Assay of Compounds 12n and 17a Using Human PR LBD and $\left[{ }^{3} \mathrm{H}\right]-\mathrm{P} 4$

The concentration of $\left[{ }^{3} \mathrm{H}\right]-\mathrm{P} 4$ was $4.0 \times 10^{-9} \mathrm{M}$.
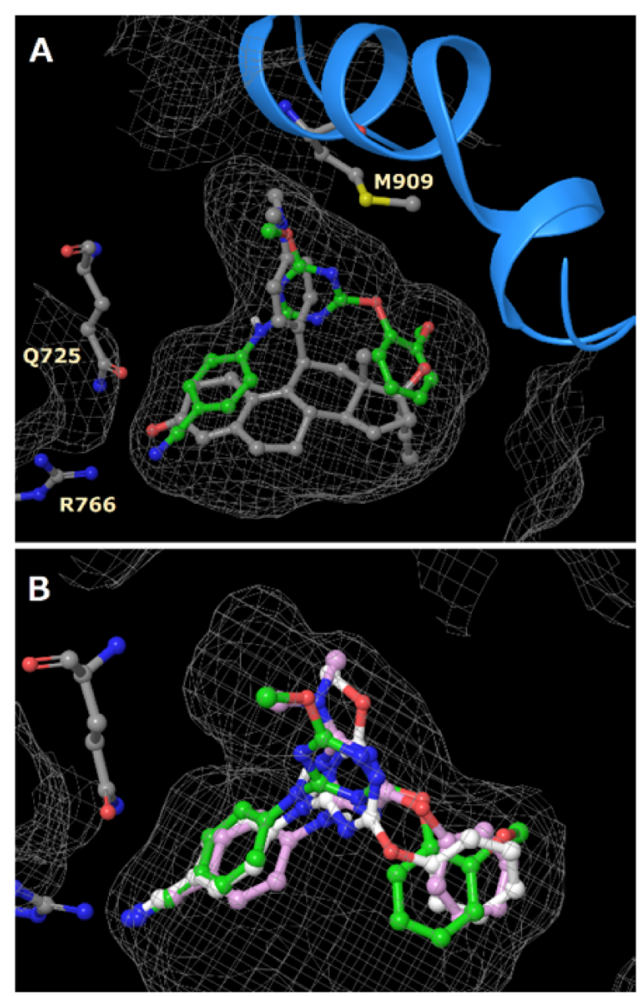

Fig. 4. Docking Models of Triazine Derivatives with the hPR-LBD (PDB ID: 2W8Y) Obtained with the Docking Program AutoDock ${ }^{33}$ )

(A) Superimposition of PR LBD binding to mifepristone (3) (carbons in gray) and docking model of $\mathbf{1 2 n}$ (carbons in green). The blue ribbon represents helix 12 of PR in the crystal structure. The protein surface is indicated by a gray mesh. (B) Superimposition of binding models of compounds 12a (carbon in white), 12n (carbon in green), and 17a (carbon in pink) at the hPR-LBD. (Color figure can be accessed in the online version.)

mifepristone (3), this seems reasonable, because $\mathbf{3}$ exhibits subnanomolar potency in the alkaline phosphatase assay ${ }^{17,18)}$; thus the binding affinity of triazine derivatives was consistent with the results of alkaline phosphatase assay. The binding data indicate that the developed compounds function as PR antagonists through binding to the PR-LBD.

Docking Simulations In order to estimate the binding mode of the developed triazine derivatives and to investigate the SAR, we conducted docking simulations, using the cocrystal structure of the hPR-LBD with mifepristone (3) (PDB
ID: $2 \mathrm{~W} 8 \mathrm{Y}){ }^{32)}$ We first investigated docking of the 2-methoxyphenyl derivative 12n, which exhibited the most potent PR-antagonistic activity among the synthesized compounds. Figure 4A shows the docking model of compound $\mathbf{1 2 n}$ with the PR-LBD, superimposed on the co-crystal structure of $\mathbf{3}$. In the calculated structure, the cyano group of $\mathbf{1 2 n}$ interacts with Gln725 and Arg766; these residues interact with the 3-carbonyl group of mifepristone (3). The 2-methoxyphenyl group occupied the hydrophobic region of the PR LBD, where the D-ring and 18-methyl group of mifepristone (3) are located. The methoxytriazine moiety of $\mathbf{1 2 n}$ was placed near helix 12 (H12) of PR, where the $11 \beta$-dimethylaminophenyl group of $\mathbf{3}$ is located in the crystal structure. The ligand-induced folding of H12 is essential for transcriptional activity of nuclear receptors, ${ }^{30)}$ and the dimethylaminophenyl group plays a key role in PR-antagonism of mifepristone (3) through steric interference with Met909 in H12, leading to destabilization of the helix. ${ }^{32}$ ) We also calculated the binding forms of compounds $\mathbf{1 2} \mathbf{a}$ and 17a. Figure $4 \mathrm{~B}$ shows the calculated structures of triazine derivatives bound to PR-LBD as a superimposition of three derivatives including 12n. The calculation suggested that compounds 12a and 17a could bind to PR similarly to $\mathbf{1 2 n}$. The dimethylamino group of $\mathbf{1 7} \mathbf{a}$ was located in the same position as the methoxy group of $\mathbf{1 2 n}$, suggesting that the dimethylaminotriazine moiety of $\mathbf{1 7} \mathbf{a}$, as well as the dimethylamino group of mifepristone (3), could interact with Met909 of PR to exert PR-antagonistic activity. As for the phenoxy moiety, the calculation suggested that the unsubstituted phenoxy group of 12a and $17 \mathbf{a}$ is located in the hydrophobic cavity of PR-LBD, and the 2-methoxyphenyl group of $\mathbf{1 2 n}$ is better able to occupy the cavity effectively. This could be one reason why substitution of the 2-position of the phenoxy group was favorable for PR-antagonistic activity of the designed triazine derivatives. Overall, the simulations suggested that the designed compounds function as PR antagonists in the expected manner, i.e., the cyanophenyl group serves as a key pharmacophore to form hydrogen bonds to the PR-LBD, and the bulkiness of the phenoxytriazine moiety is appropriate to inhibit the transcriptional activity of the receptor. The calculations also suggest avenues for further structural development. The designed compounds formed hydrogen bonds to Gln725 and Arg766 in a similar manner to mifepristone (3), but mifepristone (3) forms an additional hydrogen bond; the $17 \beta$-hydroxyl on the D-ring forms a water-mediated hydrogen bond to Asn719. ${ }^{32}$ ) Further structural optimization especially at the phenoxy moiety that corresponds to the D-ring of mifepristone (3) may lead to more potent PR-antagonistic potency (Fig. 4).

Conclusion We set out to develop a novel type of nonsteroidal PR antagonists by utilizing the 2-(4-cyanophenylamino)4-phenoxy-1,3,5-triazine scaffold as a template structure. Among the compounds synthesized, 12n exhibited most potent PR-antagonistic activity, with reasonable binding affinity to the PR-LBD. Docking simulations suggested that the 2-(4-cyanophenylamino)-4-phenoxy-1,3,5-triazine structure is a promising scaffold for PR antagonists, i.e., the cyanophenyl group functions as a key pharmacophore forming hydrogen bonds to the PR-LBD, and the bulkiness of the phenoxytriazine moiety is appropriate to inhibit the transcriptional activity of the receptor. The docking simulations also suggested avenues for further exploration. The compounds developed in this study should be useful lead compounds for further 
structural development of PR antagonists and are expected to expand the pharmaceutical potential of PR modulation.

\section{Chemistry}

General All reagents were purchased from SigmaAldrich Chemicals Co. (U.S.A.), Tokyo Kasei Co. (Japan), Wako Pure Chemical Industries, Ltd. (Japan), and Kanto Chemical Co., Inc. (Japan) Flash column chromatography was performed on silica gel 60 Kanto Kagaku $(40-100 \mu \mathrm{m})$. ${ }^{1} \mathrm{H}-\mathrm{NMR}$ spectra were recorded on a JEOL JNM-GX 500 spectrometer at $500 \mathrm{MHz}$. The following abbreviations are used for spin multiplicity: $\mathrm{s}=$ singlet, $\mathrm{d}=$ doublet, $\mathrm{t}=$ triplet, $\mathrm{q}=$ quartet, $\mathrm{m}=$ multiplet, $\mathrm{br}=$ broad. Melting points $(\mathrm{mp})$ were determined by using a MP-J3 melting point apparatus (Yanaco, Japan). Mass spectral data were obtained with a Bruker microTOF mass spectrometer. Elemental analyses were determined by using a MT-6 CHN CORDER analyzer (Yanaco, Japan), and results were within $\pm 0.4 \%$ of the theoretical values.

2,4-Dichloro-6-methoxy-1,3,5-triazine (10) Cyanuric chloride $(9.23 \mathrm{~g}, 50.0 \mathrm{mmol})$ was added to a solution of sodium hydrogen carbonate $(4.20 \mathrm{~g}, 50.0 \mathrm{mmol})$ in methanol $(200 \mathrm{~mL})$ at $0^{\circ} \mathrm{C}$. The mixture was stirred for $20 \mathrm{~min}$ at $0^{\circ} \mathrm{C}$, then poured into water and extracted with ethyl acetate. The organic layer was washed with brine, dried over sodium sulfate and concentrated. The residue was purified by recrystallization from $n$-hexane to afford $6.67 \mathrm{~g}(74 \%)$ of 2 as colorless crystals. ${ }^{1} \mathrm{H}-\mathrm{NMR}\left(500 \mathrm{MHz}, \mathrm{CDCl}_{3}\right) \delta: 4.14(3 \mathrm{H}, \mathrm{s})$.

General Procedure for the Synthesis of Compounds 11a-11p Phenol (ca. 500 mg, 1.0 eq) in dichloromethane $(5 \mathrm{~mL})$ and $N, N$-diisopropylethylamine (1.0 eq) in dichloromethane $(5 \mathrm{~mL})$ were added dropwise to a solution of 2 (1.0 eq) in dichloromethane $(10 \mathrm{~mL})$. The mixture was stirred for $30 \mathrm{~min}$ at room temperature, washed with aqueous hydrochloric acid and brine, dried over sodium sulfate and concentrated. The residue was purified by silica gel column chromatography or recrystallization.

2-Chloro-4-methoxy-6-phenoxy-1,3,5-triazine (11a)

Purification with silica gel column chromatography (eluent: $n$-hexane-ethyl acetate $10: 1)$ gave 11a $(69 \%)$ as a white solid. ${ }^{1} \mathrm{H}-\mathrm{NMR}\left(500 \mathrm{MHz}, \mathrm{CDCl}_{3}\right) \delta: 7.44(2 \mathrm{H}, \mathrm{t}, J=7.2 \mathrm{~Hz}), 7.30$ $(1 \mathrm{H}, \mathrm{t}, J=7.4 \mathrm{~Hz}), 7.18(2 \mathrm{H}, \mathrm{dq}, J=1.5,8.9 \mathrm{~Hz}), 4.02(3 \mathrm{H}, \mathrm{s})$.

2-Chloro-4-methoxy-6-(2-methylphenoxy)-1,3,5-triazine (11b)

Purification with silica gel column chromatography (eluent: $n$-hexane-ethyl acetate $10: 1)$ gave $\mathbf{1 1 b}(74 \%)$ as a white solid. ${ }^{1} \mathrm{H}-\mathrm{NMR}\left(500 \mathrm{MHz}, \mathrm{CDCl}_{3}\right) \delta: 7.28(1 \mathrm{H}, \mathrm{dd}, J=1.7$, $\mathrm{Hz}, 7.4 \mathrm{~Hz}), 7.24(1 \mathrm{H}, \mathrm{td}, J=1.7 \mathrm{~Hz}, 7.3 \mathrm{~Hz}), 7.21(1 \mathrm{H}, \mathrm{td}$, $J=1.3 \mathrm{~Hz}, 7.3 \mathrm{~Hz}), 7.07(1 \mathrm{H}, \mathrm{dd}, J=1.4 \mathrm{~Hz}, 7.7 \mathrm{~Hz}), 4.00(3 \mathrm{H}$, s), $2.19(3 \mathrm{H}, \mathrm{s})$.

2-Chloro-4-methoxy-6-(3-methylphenoxy)-1,3,5-triazine (11c)

Purification with silica gel column chromatography (eluent: $n$-hexane-ethyl acetate $5: 1)$ gave 11c $(73 \%)$ as a white solid. ${ }^{1} \mathrm{H}-\mathrm{NMR}\left(500 \mathrm{MHz}, \mathrm{CDCl}_{3}\right) \delta: 7.31(1 \mathrm{H}, \mathrm{td}, J=1.1 \mathrm{~Hz}, 7.4 \mathrm{~Hz})$, $7.10(1 \mathrm{H}, \mathrm{d}, J=7.4 \mathrm{~Hz}), 6.97(1 \mathrm{H}, \mathrm{s}), 6.96(1 \mathrm{H}, \mathrm{d}, J=6.9 \mathrm{~Hz})$, $4.02(3 \mathrm{H}, \mathrm{s}), 2.39(3 \mathrm{H}, \mathrm{s})$.

2-Chloro-4-methoxy-6-(4-methylphenoxy)-1,3,5-triazine (11d)

Purified by silica gel column chromatography (eluent: $n$ hexane-ethyl acetate 10:1) gave 11d (68\%) as colorless crys- tals. ${ }^{1} \mathrm{H}-\mathrm{NMR}\left(500 \mathrm{MHz}, \mathrm{CDCl}_{3}\right) \delta: 7.22(2 \mathrm{H}, \mathrm{d}, J=8.0 \mathrm{~Hz})$, $7.05(2 \mathrm{H}, \mathrm{td}, J=3.2 \mathrm{~Hz}, 5.6 \mathrm{~Hz}), 4.02(3 \mathrm{H}, \mathrm{s}), 2.37$ (3H, s).

2-Chloro-4-methoxy-6-(2-trifluoromethylphenoxy)-1,3,5triazine (11e)

Purification with silica gel column chromatography (eluent: $n$-hexane-ethyl acetate $5: 1)$ gave 11e $(63 \%)$ as a white solid. ${ }^{1} \mathrm{H}-\mathrm{NMR}\left(500 \mathrm{MHz}, \mathrm{CDCl}_{3}\right) \delta$ : $7.74(1 \mathrm{H}, \mathrm{d}, J=7.4 \mathrm{~Hz})$, $7.65(1 \mathrm{H}, \mathrm{t}, J=7.7 \mathrm{~Hz}), 7.43(1 \mathrm{H}, \mathrm{t}, J=7.7 \mathrm{~Hz}), 7.27(1 \mathrm{H}, \mathrm{d}$, $J=8.0 \mathrm{~Hz}), 4.02(3 \mathrm{H}, s)$.

2-Chloro-4-methoxy-6-(3-trifluoromethylphenoxy)-1,3,5triazine (11f)

Purification with silica gel column chromatography (eluent: $n$-hexane-ethyl acetate $10: 1)$ gave $\mathbf{1 1 f}(39 \%)$ as colorless crystals. ${ }^{1} \mathrm{H}-\mathrm{NMR}\left(500 \mathrm{MHz}, \mathrm{CDCl}_{3}\right) \delta: 7.58(1 \mathrm{H}, \mathrm{d}, J=4.0 \mathrm{~Hz})$, $7.57(1 \mathrm{H}, \mathrm{t}, J=6.9 \mathrm{~Hz}), 7.48(1 \mathrm{H}, \mathrm{s}), 7.39(1 \mathrm{H}, \mathrm{m}), 4.03(3 \mathrm{H}, \mathrm{s})$.

2-Chloro-4-methoxy-6-(4-trifluoromethylphenoxy)-1,3,5triazine (11g)

Purification with silica gel column chromatography (eluent: $n$-hexane-ethyl acetate $10: 1)$ gave $\mathbf{1 1 g}(40 \%)$ as a white solid. ${ }^{1} \mathrm{H}-\mathrm{NMR}\left(500 \mathrm{MHz}, \mathrm{CDCl}_{3}\right) \delta: 7.72(2 \mathrm{H}, \mathrm{d}, J=8.6 \mathrm{~Hz}), 7.32$ $(2 \mathrm{H}, \mathrm{d}, J=8.0 \mathrm{~Hz}), 4.05(3 \mathrm{H}, \mathrm{s})$.

2-(2-Fluorophenoxy)-4-chloro-6-methoxy-1,3,5-triazine (11h)

Recrystallization from $n$-hexane-chloroform gave $\mathbf{1 1 h}$ $(59 \%)$ as colorless crystals. ${ }^{1} \mathrm{H}-\mathrm{NMR}\left(500 \mathrm{MHz}, \mathrm{CDCl}_{3}\right) \delta$ : 7.29 (1H, m), 7.26-7.18 (3H, m), 4.02 (3H, s).

2-(3-Fluorophenoxy)-4-chloro-6-methoxy-1,3,5-triazine (11i)

Recrystallization from $n$-hexane-chloroform gave 11i (53\%) as colorless crystals. ${ }^{1} \mathrm{H}-\mathrm{NMR}\left(500 \mathrm{MHz}, \mathrm{CDCl}_{3}\right) \delta: 7.40(1 \mathrm{H}$, $\mathrm{td}, J=6.7,8.3 \mathrm{~Hz}), 7.03-6.98(3 \mathrm{H}, \mathrm{m}), 4.04(3 \mathrm{H}, \mathrm{s})$.

2-(4-Fluorophenoxy)-4-chloro-6-methoxy-1,3,5-triazine (11j)

Recrystallization from $n$-hexane-chloroform gave 11j (68\%) as colorless crystals. ${ }^{1} \mathrm{H}-\mathrm{NMR}\left(500 \mathrm{MHz}, \mathrm{CDCl}_{3}\right) \delta$ : $7.16-7.10$ $(4 \mathrm{H}, \mathrm{m}), 7.48(1 \mathrm{H}, \mathrm{s}), 4.03(3 \mathrm{H}, \mathrm{s})$.

2-(2-Acetylphenoxy)-4-chloro-6-methoxy-1,3,5-triazine (11k)

Purification with silica gel column chromatography (eluent: $n$-hexane-ethyl acetate $3: 1)$ gave $\mathbf{1 1 k}(34 \%)$ as a pale yellow solid. ${ }^{1} \mathrm{H}-\mathrm{NMR}\left(500 \mathrm{MHz}, \mathrm{CDCl}_{3}\right) \delta: 7.88(1 \mathrm{H}, \mathrm{dd}, J=1.4 \mathrm{~Hz}$, $7.7 \mathrm{~Hz}), 7.61(1 \mathrm{H}, \mathrm{td}, J=1.7 \mathrm{~Hz}, 7.7 \mathrm{~Hz}), 7.42(1 \mathrm{H}, \mathrm{t}, J=7.7 \mathrm{~Hz})$, $7.22(1 \mathrm{H}, \mathrm{d}, J=8.6 \mathrm{~Hz}), 4.02(3 \mathrm{H}, \mathrm{s}), 2.54(3 \mathrm{H}, \mathrm{s})$.

2-(3-Acetylphenoxy)-4-chloro-6-methoxy-1,3,5-triazine (111)

Purification with silica gel column chromatography (eluent: $n$-hexane-ethyl acetate $6: 4)$ gave $\mathbf{1 1 l}(79 \%)$ as a yellow solid. ${ }^{1} \mathrm{H}-\mathrm{NMR}\left(500 \mathrm{MHz}, \mathrm{CDCl}_{3}\right) \delta: 7.90(1 \mathrm{H}, \mathrm{d}, J=6.9 \mathrm{~Hz})$, $7.78(1 \mathrm{H}, \mathrm{t}, J=1.7 \mathrm{~Hz}), 7.55(1 \mathrm{H}, \mathrm{t}, J=7.7 \mathrm{~Hz}), 7.39(1 \mathrm{H}, \mathrm{dt}$, $J=1.4 \mathrm{~Hz}, 8.0 \mathrm{~Hz}), 4.03(3 \mathrm{H}, \mathrm{s}), 2.62(3 \mathrm{H}, \mathrm{s})$.

2-(4-Acetylphenoxy)-4-chloro-6-methoxy-1,3,5-triazine (11m)

Recrystallization from $n$-hexane-chloroform gave $\mathbf{1 1} \mathbf{m}$ $(53 \%)$ as colorless crystals. ${ }^{1} \mathrm{H}-\mathrm{NMR}\left(500 \mathrm{MHz}, \mathrm{CDCl}_{3}\right) \delta$ : $8.06(2 \mathrm{H}, \mathrm{dt}, J=2.3 \mathrm{~Hz}, 9.4 \mathrm{~Hz}), 7.29(2 \mathrm{H}, \mathrm{dt}, J=2.3 \mathrm{~Hz}$, $9.2 \mathrm{~Hz}), 4.04(3 \mathrm{H}, \mathrm{s}), 2.63(3 \mathrm{H}, \mathrm{s})$.

2-Chloro-4-methoxy-6-(2-methoxyphenoxy)-1,3,5-triazine (11n)

Purification with silica gel column chromatography (eluent: n-hexane-ethyl acetate $5: 1)$ gave $11 n(70 \%)$ as a white solid. ${ }^{1} \mathrm{H}-\mathrm{NMR}\left(500 \mathrm{MHz}, \mathrm{CDCl}_{3}\right) \delta: 7.27(1 \mathrm{H}, \mathrm{t}, J=7.7 \mathrm{~Hz}), 7.14$ 
$(1 \mathrm{H}, \mathrm{dd}, J=1.4 \mathrm{~Hz}, 7.7 \mathrm{~Hz}), 7.01(1 \mathrm{H}, \mathrm{t}, J=8.0 \mathrm{~Hz}), 6.99(1 \mathrm{H}, \mathrm{t}$, $J=7.7 \mathrm{~Hz}), 4.00(3 \mathrm{H}, \mathrm{s}), 3.79(3 \mathrm{H}, \mathrm{s})$.

2-Chloro-4-methoxy-6-(3-methoxyphenoxy)-1,3,5-triazine (110)

Purification with silica gel column chromatography (eluent: $n$-hexane-ethyl acetate $3: 1)$ gave $\mathbf{1 1 0}(50 \%)$ as a yellow solid. ${ }^{1} \mathrm{H}-\mathrm{NMR}\left(500 \mathrm{MHz}, \mathrm{CDCl}_{3}\right) \delta: 7.33(1 \mathrm{H}, \mathrm{t}, J=8.0 \mathrm{~Hz}), 6.84$ $(1 \mathrm{H}, \mathrm{dd}, J=2.6 \mathrm{~Hz}, 8.3 \mathrm{~Hz}), 6.77(1 \mathrm{H}, \mathrm{dd}, J=2.3 \mathrm{~Hz}, 7.4 \mathrm{~Hz})$, $6.72(1 \mathrm{H}, \mathrm{t}, J=2.3 \mathrm{~Hz}), 4.02(3 \mathrm{H}, \mathrm{s}), 3.82(3 \mathrm{H}, \mathrm{s})$.

2-Chloro-4-methoxy-6-(4-methoxyphenoxy)-1,3,5-triazine (11p)

Recrystallization from $n$-hexane-ethyl acetate gave $\mathbf{1 1 p}$ $(67 \%)$ as white crystals. ${ }^{1} \mathrm{H}-\mathrm{NMR}\left(500 \mathrm{MHz}, \mathrm{CDCl}_{3}\right) \delta: 7.09$ $(2 \mathrm{H}, \mathrm{td}, J=3.8 \mathrm{~Hz}, 6.3 \mathrm{~Hz}), 6.93(2 \mathrm{H}, \mathrm{td}, J=4.0 \mathrm{~Hz}, 6.4 \mathrm{~Hz})$, $4.02(3 \mathrm{H}, \mathrm{s}), 3.83(3 \mathrm{H}, \mathrm{s})$.

General Procedure for the Synthesis of Compounds 12a-12p [Method A] To a solution of a compound (11a, 11e-11j, ca. $250 \mathrm{mg}, 1.0 \mathrm{eq})$ in tetrahydrofuran (THF) $(1.0 \mathrm{~mL})$ were added 4 -aminobenzonitrile (2.0 eq) and $N, N$-diisopropylethylamine $(2.0 \mathrm{eq})$ at room temperature. The mixture was refluxed for $5 \mathrm{~h}$, then poured into dilute hydrochloric acid and extracted with ethyl acetate. The organic layer washed with brine, dried over sodium sulfate and concentrated. The residue was purified by recrystallization. [Method B] To a solution of a compound (11b-11d, 11k) ca. $250 \mathrm{mg}, 1.0 \mathrm{eq})$ in dimethyl sulfoxide (DMSO) $(1.0 \mathrm{~mL})$ were added 4-aminobenzonitrile (2 eq) and $N, N$-diisopropylethylamine $(2.0 \mathrm{eq})$ at room temperature. The mixture was stirred for $3 \mathrm{~h}$ at $100^{\circ} \mathrm{C}$, and then poured into chloroform. The organic layer was washed with brine, dried over sodium sulfate and concentrated. The residue was purified by recrystallization.

2-(4-Cyanoanilino)-4-methoxy-6-phenoxy-1,3,5-triazine (12a)

Method A. Recrystallization from methanol gave 12a (50\%) as colorless crystals. mp $197.7-198.5^{\circ} \mathrm{C}$; ${ }^{1} \mathrm{H}-\mathrm{NMR}(500 \mathrm{MHz}$, $\left.\mathrm{CDCl}_{3}\right) \delta: 7.53(4 \mathrm{H}, \mathrm{br}), 7.46(2 \mathrm{H}, \mathrm{t}, J=8.0 \mathrm{~Hz}), 7.33(1 \mathrm{H}$, t, $J=7.2 \mathrm{~Hz}), 7.20(2 \mathrm{H}, \mathrm{d}, J=7.4 \mathrm{~Hz}), 3.49(3 \mathrm{H}, \mathrm{s})$. High resolution (HR)-MS (electrospray ionization-time of flight (ESI-TOF)) $m / z$ : $318.0974\left([\mathrm{M}-\mathrm{H}]^{-}\right.$Calcd for $\mathrm{C}_{17} \mathrm{H}_{13} \mathrm{~N}_{5} \mathrm{O}_{2}$ : 318.0986). Anal. Calcd for $\mathrm{C}_{17} \mathrm{H}_{13} \mathrm{~N}_{5} \mathrm{O}_{2}: \mathrm{C}, 63.94 ; \mathrm{H}, 4.10 ; \mathrm{N}$, 21.93. Found: C, 63.99; H, 4.38; N, 21.91.

2-(4-Cyanoanilino)-4-methoxy-6-(2-methylphenoxy)-1,3,5triazine (12b)

Method B. Recrystallization from methanol gave 12b (33\%) as colorless crystals. mp $170.3-171.2^{\circ} \mathrm{C} ;{ }^{1} \mathrm{H}-\mathrm{NMR}(500 \mathrm{MHz}$, $\left.\mathrm{CDCl}_{3}\right) \delta: 7.55(1 \mathrm{H}, \mathrm{s}), 7.48(4 \mathrm{H}, \mathrm{br}), 7.29(1 \mathrm{H}, \mathrm{t}, J=8.9 \mathrm{~Hz})$, $7.27(1 \mathrm{H}, \mathrm{d}, J=8.0 \mathrm{~Hz}), 7.24(1 \mathrm{H}, \mathrm{t}, J=7.2 \mathrm{~Hz}), 7.10(1 \mathrm{H}, \mathrm{d}$, $J=8.0 \mathrm{~Hz}), 4.02(3 \mathrm{H}, \mathrm{s}), 2.21(3 \mathrm{H}, \mathrm{s})$. HR-MS (ESI-TOF) $\mathrm{m} / \mathrm{z}$ : $332.1160\left([\mathrm{M}-\mathrm{H}]^{-}\right.$Calcd for $\mathrm{C}_{18} \mathrm{H}_{15} \mathrm{~N}_{5} \mathrm{O}_{2}$ : 332.1142). Anal. Calcd for $\mathrm{C}_{18} \mathrm{H}_{15} \mathrm{~N}_{5} \mathrm{O}_{2}: \mathrm{C}, 64.86 ; \mathrm{H}, 4.54 ; \mathrm{N}, 21.01$. Found: $\mathrm{C}$, 64.58; H, 4.61; N, 21.03.

2-(4-Cyanoanilino)-4-methoxy-6-(3-methylphenoxy)-1,3,5triazine (12c)

Method B. Recrystallization from methanol gave 12c (18\%) as a white solid. mp $182.0-183.5^{\circ} \mathrm{C}$; ${ }^{1} \mathrm{H}-\mathrm{NMR}(500 \mathrm{MHz}$, $\left.\mathrm{CDCl}_{3}\right) \delta: 7.49(5 \mathrm{H}, \mathrm{br}), 7.33(1 \mathrm{H}, \mathrm{t}, J=7.7 \mathrm{~Hz}), 7.14(1 \mathrm{H}, \mathrm{d}$, $J=7.4 \mathrm{~Hz}), 7.00(1 \mathrm{H}, \mathrm{d}, J=8.6 \mathrm{~Hz}), 7.00(1 \mathrm{H}, \mathrm{s}), 4.02(3 \mathrm{H}, \mathrm{s})$, $2.40(3 \mathrm{H}, \mathrm{s})$. HR-MS (ESI-TOF) $m / z: 332.1140\left([\mathrm{M}-\mathrm{H}]^{-}\right.$Calcd for $\mathrm{C}_{18} \mathrm{H}_{15} \mathrm{~N}_{5} \mathrm{O}_{2}$ 332.1142). Anal. Calcd for $\mathrm{C}_{18} \mathrm{H}_{15} \mathrm{~N}_{5} \mathrm{O}_{2}$ : C, 64.86; H, 4.54; N, 21.01. Found: C, 65.00; H, 4.75; N, 21.03.
2-(4-Cyanoanilino)-4-methoxy-6-(4-methylphenoxy)-1,3,5triazine (12d)

Method B. Recrystallization from methanol gave 12d $(41 \%)$ as colorless crystals. mp $189.9-191.2^{\circ} \mathrm{C}$; ${ }^{1} \mathrm{H}-\mathrm{NMR}$ $\left(500 \mathrm{MHz}, \mathrm{CDCl}_{3}\right) \delta: 7.52(4 \mathrm{H}, \mathrm{br}), 7.41(1 \mathrm{H}, \mathrm{s}), 7.24(2 \mathrm{H}, \mathrm{d}$, $J=8.0 \mathrm{~Hz}), 7.08(2 \mathrm{H}, \mathrm{td}, J=3.4 \mathrm{~Hz}, 5.7 \mathrm{~Hz}), 4.02(3 \mathrm{H}, \mathrm{s}), 2.41$ $(3 \mathrm{H}, \mathrm{s})$. HR-MS (ESI-TOF) $\mathrm{m} / \mathrm{z}: 332.1140\left([\mathrm{M}-\mathrm{H}]^{-}\right.$Calcd for $\mathrm{C}_{18} \mathrm{H}_{15} \mathrm{~N}_{5} \mathrm{O}_{2}$ 332.1142). Anal. Calcd for $\mathrm{C}_{18} \mathrm{H}_{15} \mathrm{~N}_{5} \mathrm{O}_{2}$ : C, 64.86; H, 4.54; N, 21.01. Found: C, 64.80; H, 4.67; N, 20.99.

2-(4-Cyanoanilino)-4-methoxy-6-(2-trifluoromethylphenoxy)1,3,5-triazine (12e)

Method A. Recrystallization from methanol gave 12e (53\%) as colorless crystals. mp $196.0-197.2{ }^{\circ} \mathrm{C} ;{ }^{1} \mathrm{H}-\mathrm{NMR}(500 \mathrm{MHz}$, $\left.\mathrm{CDCl}_{3}\right) \delta: 7.75(1 \mathrm{H}, \mathrm{d}, J=8.0 \mathrm{~Hz}), 7.65(1 \mathrm{H}, \mathrm{t}, J=7.7 \mathrm{~Hz}), 7.53$ $(5 \mathrm{H}, \mathrm{br}), 7.44(1 \mathrm{H}, \mathrm{t}, J=7.4 \mathrm{~Hz}), 7.29(1 \mathrm{H}, \mathrm{d}, J=8.6 \mathrm{~Hz}), 4.01$ $(3 \mathrm{H}, \mathrm{s})$. HR-MS (ESI-TOF) $\mathrm{m} / \mathrm{z}: 386.0862\left([\mathrm{M}-\mathrm{H}]^{-}\right.$Calcd for $\mathrm{C}_{18} \mathrm{H}_{12} \mathrm{~F}_{3} \mathrm{~N}_{5} \mathrm{O}_{2}$ 386.0859). Anal. Calcd for $\mathrm{C}_{18} \mathrm{H}_{12} \mathrm{~F}_{3} \mathrm{~N}_{5} \mathrm{O}_{2}$ : C, 55.82; H, 3.12; N, 18.08. Found: C, 55.81; H, 3.40; N, 18.09.

2-(4-Cyanoanilino)-4-methoxy-6-(3-trifluoromethylphenoxy)1,3,5-triazine (12f)

Method A. Recrystallization from methanol gave $\mathbf{1 2 f}(16 \%)$ as a white solid. mp $192.5-193.8^{\circ} \mathrm{C}$; ${ }^{1} \mathrm{H}-\mathrm{NMR}(500 \mathrm{MHz}$, $\left.\mathrm{CDCl}_{3}\right) \delta: 7.63-7.39(9 \mathrm{H}, \mathrm{m}), 4.02(3 \mathrm{H}, \mathrm{s}) . \mathrm{HR}-\mathrm{MS}$ (ESI-TOF) $m / z$ : $386.0878\left([\mathrm{M}-\mathrm{H}]^{-}\right.$Calcd for $\mathrm{C}_{18} \mathrm{H}_{12} \mathrm{~F}_{3} \mathrm{~N}_{5} \mathrm{O}_{2}$ 386.0859). Anal. Calcd for $\mathrm{C}_{18} \mathrm{H}_{12} \mathrm{~F}_{3} \mathrm{~N}_{5} \mathrm{O}_{2}$ : C, 55.82; H, 3.12; N, 18.08. Found: C, 55.91; H, 3.31; N, 18.10.

2-(4-Cyanoanilino)-4-methoxy-6-(4trifluoromethylphenoxy)1,3,5-triazine $(\mathbf{1 2 g})$

Method A. Recrystallization from methanol gave 12g (14\%) as colorless crystals. mp $200.2-202.0{ }^{\circ} \mathrm{C} ;{ }^{1} \mathrm{H}-\mathrm{NMR}(500 \mathrm{MHz}$, $\left.\mathrm{CDCl}_{3}\right) \delta: 7.73(2 \mathrm{H}, \mathrm{d}, J=8.6 \mathrm{~Hz}), 7.56(4 \mathrm{H}, \mathrm{br}), 7.42(1 \mathrm{H}, \mathrm{s})$, $7.33(2 \mathrm{H}, \mathrm{d}, J=8.0 \mathrm{~Hz}), 4.02(3 \mathrm{H}, \mathrm{s})$. HR-MS (ESI-TOF) $\mathrm{m} / \mathrm{z}$ : $386.0871\left([\mathrm{M}-\mathrm{H}]^{-}\right.$Calcd for $\mathrm{C}_{18} \mathrm{H}_{12} \mathrm{~F}_{3} \mathrm{~N}_{5} \mathrm{O}_{2}$ 386.0859). Anal. Calcd for $\mathrm{C}_{18} \mathrm{H}_{12} \mathrm{~F}_{3} \mathrm{~N}_{5} \mathrm{O}_{2}$ : C, 55.82; H, 3.12; N, 18.08. Found: C, 55.74; H, 3.33; N, 18.13 .

2-(4-Cyanoanilino)-4-(2-fluorophenoxy)-6-methoxy-1,3,5triazine (12h)

Method A. Recrystallization from methanol gave $\mathbf{1 2 h}$ $(31 \%)$ as colorless crystals. mp $204.5-206.0^{\circ} \mathrm{C}$; ${ }^{1} \mathrm{H}-\mathrm{NMR}$ $\left(500 \mathrm{MHz}, \mathrm{CDCl}_{3}\right) \delta: 7.52(5 \mathrm{H}, \mathrm{br}), 7.32-7.20(4 \mathrm{H}, \mathrm{m}), 4.02$ $(3 \mathrm{H}, \mathrm{s})$. HR-MS (ESI-TOF) $\mathrm{m} / \mathrm{z}: 336.0896\left([\mathrm{M}-\mathrm{H}]^{-} \mathrm{Calcd}\right.$ for $\mathrm{C}_{17} \mathrm{H}_{12} \mathrm{FN}_{5} \mathrm{O}_{2}$ 336.0891). Anal. Calcd for $\mathrm{C}_{17} \mathrm{H}_{12} \mathrm{FN}_{5} \mathrm{O}_{2}: \mathrm{C}$, 60.53; H, 3.59; N, 20.76. Found: C, 60.49; H, 3.84; N, 20.71.

2-(4-Cyanoanilino)-4-(3-fluorophenoxy)-6-methoxy-1,3,5triazine (12i)

Method A. Recrystallization from methanol gave 12i (8\%) as a white solid. mp $185.8-187.0^{\circ} \mathrm{C}$; ${ }^{1} \mathrm{H}-\mathrm{NMR} \quad(500 \mathrm{MHz}$, $\left.\mathrm{CDCl}_{3}\right) \delta: 7.56(4 \mathrm{H}, \mathrm{br}), 7.48(1 \mathrm{H}, \mathrm{s}), 7.41(1 \mathrm{H}, \mathrm{q}, J=7.6 \mathrm{~Hz})$, $7.05(1 \mathrm{H}, \mathrm{t}, J=8.0 \mathrm{~Hz}), 7.01(1 \mathrm{H}, \mathrm{d}, J=8.0 \mathrm{~Hz}), 6.97(1 \mathrm{H}, \mathrm{dt}$, $J=2.3,9.2 \mathrm{~Hz}$ ), $4.02(3 \mathrm{H}, \mathrm{s})$. HR-MS (ESI-TOF) $\mathrm{m} / \mathrm{z}: 336.0887$ $\left([\mathrm{M}-\mathrm{H}]^{-}\right.$Calcd for $\mathrm{C}_{17} \mathrm{H}_{12} \mathrm{FN}_{5} \mathrm{O}_{2}$ 336.0891). Anal. Calcd for $\mathrm{C}_{17} \mathrm{H}_{12} \mathrm{FN}_{5} \mathrm{O}_{2}$ : C, 60.53; H, 3.59; N, 20.76. Found: C, 60.51; H, $3.93 ; \mathrm{N}, 20.67$.

2-(4-Cyanoanilino)-4-(4-fluorophenoxy)-6-methoxy-1,3,5triazine $(\mathbf{1 2} \mathbf{j})$

Method A. Recrystallization from methanol gave 12j (60\%) as colorless crystals. mp $210.8-211.6^{\circ} \mathrm{C}$; ${ }^{1} \mathrm{H}-\mathrm{NMR}(500 \mathrm{MHz}$, $\left.\mathrm{CDCl}_{3}\right) \delta: 7.56$ (4H, br), $7.40(1 \mathrm{H}, \mathrm{s}), 7.18-7.11(4 \mathrm{H}, \mathrm{m}), 4.02$ $\left(3 \mathrm{H}\right.$, s). HR-MS (ESI-TOF) $\mathrm{m} / z$ : $336.0894\left([\mathrm{M}-\mathrm{H}]^{-}\right.$Calcd for $\mathrm{C}_{17} \mathrm{H}_{12} \mathrm{FN}_{5} \mathrm{O}_{2}$ 336.0891). Anal. Calcd for $\mathrm{C}_{17} \mathrm{H}_{12} \mathrm{FN}_{5} \mathrm{O}_{2}$ : C, 60.53; H, 3.59; N, 20.76. Found: C, 60.51; H, 3.88; N, 20.76. 
2-(2-Acetylphenoxy)-4-(4-cyanoanilino)-6-methoxy-1,3,5triazine (12k)

Method B. Recrystallization from methanol gave 12k (43\%) as colorless crystals. mp $200.8-202.5^{\circ} \mathrm{C} ;{ }^{1} \mathrm{H}-\mathrm{NMR}(500 \mathrm{MHz}$, $\left.\mathrm{CDCl}_{3}\right) \delta: 7.89(1 \mathrm{H}, \mathrm{d}, J=7.4 \mathrm{~Hz}), 7.70(1 \mathrm{H}, \mathrm{s}), 7.61(1 \mathrm{H}, \mathrm{t}$, $J=7.7 \mathrm{~Hz}), 7.51(4 \mathrm{H}, \mathrm{br}), 7.43(1 \mathrm{H}, \mathrm{t}, J=7.4 \mathrm{~Hz}), 7.23(1 \mathrm{H}$, d, $J=8.0 \mathrm{~Hz}), 3.99(3 \mathrm{H}, \mathrm{s}), 2.54(3 \mathrm{H}, \mathrm{s}) . \mathrm{HR}-\mathrm{MS}$ (ESI-TOF) m/z: $360.1091\left([\mathrm{M}-\mathrm{H}]^{-}\right.$Calcd for $\mathrm{C}_{19} \mathrm{H}_{15} \mathrm{~N}_{5} \mathrm{O}_{3}$ 360.1091). Anal. Calcd for $\mathrm{C}_{19} \mathrm{H}_{15} \mathrm{~N}_{5} \mathrm{O}_{3}$ : C, 63.15; H, 4.18; N, 19.38. Found: C, 62.97; H, 4.39; N, 19.21.

2-(3-Acetylphenoxy)-4-(4-cyanoanilino)-6-methoxy-1,3,5triazine $(\mathbf{1 2 l})$

Method A. Recrystallization from methanol gave 12l (46\%) as colorless crystals. mp $205.7-206.4^{\circ} \mathrm{C} ;{ }^{1} \mathrm{H}-\mathrm{NMR}(500 \mathrm{MHz}$, $\left.\mathrm{CDCl}_{3}\right) \delta: 7.90(1 \mathrm{H}, \mathrm{d}, J=7.4 \mathrm{~Hz}), 7.59(1 \mathrm{H}, \mathrm{s}), 7.56(1 \mathrm{H}, t$, $J=7.7 \mathrm{~Hz}), 7.55(5 \mathrm{H}, \mathrm{br}), 7.41(1 \mathrm{H}, \mathrm{dd}, J=1.1 \mathrm{~Hz}, 8.0 \mathrm{~Hz})$, 4.02 (3H, s), 2.63 (3H, s). HR-MS (ESI-TOF) m/z: 360.1091 $\left([\mathrm{M}-\mathrm{H}]^{-}\right.$Calcd for $\mathrm{C}_{19} \mathrm{H}_{15} \mathrm{~N}_{5} \mathrm{O}_{3}$ 360.1091). Anal. Calcd for $\mathrm{C}_{19} \mathrm{H}_{15} \mathrm{~N}_{5} \mathrm{O}_{3}$ : C, 63.15; H, 4.18; N, 19.38. Found: C, 63.01; H, $4.50 ; \mathrm{N}, 19.15$.

2-(4-Acetylphenoxy)-4-(4-cyanoanilino)-6-methoxy-1,3,5triazine $(\mathbf{1 2 m})$

Method A. Recrystallization from methanol gave 12 m (9\%) as a white solid. mp $229.0^{\circ} \mathrm{C}-229.8^{\circ} \mathrm{C}$; ${ }^{1} \mathrm{H}-\mathrm{NMR}(500 \mathrm{MHz}$, $\left.\mathrm{CDCl}_{3}\right) \delta: 8.06(2 \mathrm{H}, \mathrm{dt}, J=2.3 \mathrm{~Hz}, 9.0 \mathrm{~Hz}), 7.57$ (4H, br), 7.45 $(1 \mathrm{H}, \mathrm{s}), 7.30(2 \mathrm{H}, \mathrm{dt}, J=2.3 \mathrm{~Hz}, 9.4 \mathrm{~Hz}), 4.02(3 \mathrm{H}, \mathrm{s}), 2.65$ $(3 \mathrm{H}, \mathrm{s})$. HR-MS (ESI-TOF) $\mathrm{m} / \mathrm{z}: 360.1075\left([\mathrm{M}-\mathrm{H}]^{-}\right.$Calcd for $\mathrm{C}_{19} \mathrm{H}_{15} \mathrm{~N}_{5} \mathrm{O}_{3}$ 360.1091). Anal. Calcd for $\mathrm{C}_{19} \mathrm{H}_{15} \mathrm{~N}_{5} \mathrm{O}_{3}$ : C, 63.15; H, 4.18; N, 19.38. Found: C, 63.08; H, 4.45; N, 19.26.

2-(4-Cyanoanilino)-4-methoxy-6-(2-methoxyphenoxy)1,3,5-triazine $(\mathbf{1 2 n})$

Method A. Recrystallization from methanol gave 12n (14\%) as colorless crystals. mp $165.2-166.8^{\circ} \mathrm{C} ;{ }^{1} \mathrm{H}-\mathrm{NMR}(500 \mathrm{MHz}$, $\left.\mathrm{CDCl}_{3}\right) \delta: 7.69(1 \mathrm{H}, \mathrm{br}), 7.48(4 \mathrm{H}, \mathrm{br}), 7.30(1 \mathrm{H}, \mathrm{t}, J=7.7 \mathrm{~Hz})$, $7.17(1 \mathrm{H}, \mathrm{dd}, J=1.7 \mathrm{~Hz}, 8.0 \mathrm{~Hz}), 7.04(1 \mathrm{H}, \mathrm{d}, J=8.6 \mathrm{~Hz})$, $7.02(1 \mathrm{H}, \mathrm{t}, J=7.7 \mathrm{~Hz}), 4.01(3 \mathrm{H}, \mathrm{s}), 3.79(3 \mathrm{H}, \mathrm{s}) . \mathrm{HR}-\mathrm{MS}$ (ESI-TOF) $\mathrm{m} / \mathrm{z}$ : $348.1087\left([\mathrm{M}-\mathrm{H}]^{-}\right.$Calcd for $\mathrm{C}_{18} \mathrm{H}_{15} \mathrm{~N}_{5} \mathrm{O}_{3}$ 348.1091)). Anal. Calcd for $\mathrm{C}_{18} \mathrm{H}_{15} \mathrm{~N}_{5} \mathrm{O}_{3}: \mathrm{C}, 61.89 ; \mathrm{H}, 4.33 ; \mathrm{N}$, 20.05. Found: C, 61.96; H, 4.50; N, 20.15.

2-(4-Cyanoanilino)-4-methoxy-6-(3-methoxyphenoxy)1,3,5-triazine $(\mathbf{1 2 0})$

Method A. Recrystallization from methanol gave 120 (44\%) as colorless crystals. mp $163.7-164.5^{\circ} \mathrm{C} ;{ }^{1} \mathrm{H}-\mathrm{NMR}(500 \mathrm{MHz}$, $\left.\mathrm{CDCl}_{3}\right) \delta: 7.53(4 \mathrm{H}, \mathrm{br}), 7.42(1 \mathrm{H}, \mathrm{s}), 7.35(1 \mathrm{H}, \mathrm{t}, J=8.0 \mathrm{~Hz})$, $6.87(1 \mathrm{H}, \mathrm{d}, J=8.0 \mathrm{~Hz}), 6.80(1 \mathrm{H}, \mathrm{dd}, J=2.0 \mathrm{~Hz}, 8.6 \mathrm{~Hz}), 6.76$ $(1 \mathrm{H}, \mathrm{t}, J=2.3 \mathrm{~Hz}), 4.03(3 \mathrm{H}, \mathrm{s}), 3.82(3 \mathrm{H}, \mathrm{s})$. HR-MS (ESITOF) $m / z$ : $348.1101\left([\mathrm{M}-\mathrm{H}]^{-}\right.$Calcd for $\left.\mathrm{C}_{18} \mathrm{H}_{15} \mathrm{~N}_{5} \mathrm{O}_{3} 348.1091\right)$. Anal. Calcd for $\mathrm{C}_{18} \mathrm{H}_{15} \mathrm{~N}_{5} \mathrm{O}_{3}$ : C, 61.89; H, 4.33; N, 20.05. Found: C, 61.96; H, 4.45; N, 20.10.

2-(4-Cyanoanilino)-4-methoxy-6-(4-methoxyphenoxy)1,3,5-triazine $(\mathbf{1 2 p})$

Method A. Recrystallization from methanol gave 12p (28\%) as colorless crystals. mp $174.2-175.5^{\circ} \mathrm{C}$; ${ }^{1} \mathrm{H}-\mathrm{NMR}(500 \mathrm{MHz}$, $\left.\mathrm{CDCl}_{3}\right) \delta: 7.54(4 \mathrm{H}, \mathrm{br}), 7.37(1 \mathrm{H}, \mathrm{s}), 7.11(2 \mathrm{H}, \mathrm{td}, J=4.0 \mathrm{~Hz}$, $6.4 \mathrm{~Hz}), 6.95(2 \mathrm{H}, \mathrm{td}, J=3.8 \mathrm{~Hz}, 6.3 \mathrm{~Hz}), 4.02(3 \mathrm{H}, \mathrm{s}), 3.85$ $(3 \mathrm{H}, \mathrm{s})$. HR-MS (ESI-TOF) $\mathrm{m} / \mathrm{z}: 348.1095\left([\mathrm{M}-\mathrm{H}]^{-}\right.$Calcd for $\mathrm{C}_{18} \mathrm{H}_{15} \mathrm{~N}_{5} \mathrm{O}_{3}$ 348.1091). Anal. Calcd for $\mathrm{C}_{18} \mathrm{H}_{15} \mathrm{~N}_{5} \mathrm{O}_{3}$ : C, 61.89; H, 4.33; N, 20.05. Found: C, 61.94; H, 4.44; N, 19.92

2,4-Dichloro-6-ethoxy-1,3,5-triazine (13a) Cyanuric chloride $(1.86 \mathrm{~g}, 10.1 \mathrm{mmol})$ was added to a solution of sodium hydrogen carbonate $(843 \mathrm{mg}, 10.0 \mathrm{mmol}, 0.99 \mathrm{eq})$ in ethanol
$(40 \mathrm{~mL})$ at $0^{\circ} \mathrm{C}$. The mixture was stirred for $25 \mathrm{~min}$ at $0^{\circ} \mathrm{C}$, then poured into water and extracted with ethyl acetate. The organic layer was washed with brine, dried over sodium sulfate and concentrated. The residue was purified by recrystallization from $n$-hexane to afford $493 \mathrm{mg}(2.54 \mathrm{mmol}, 25 \%)$ of 13a as colorless crystals. ${ }^{1} \mathrm{H}-\mathrm{NMR}\left(500 \mathrm{MHz}, \mathrm{CDCl}_{3}\right) \delta: 4.57$ $(2 \mathrm{H}, \mathrm{q}, J=7.3 \mathrm{~Hz}), 1.47(3 \mathrm{H}, \mathrm{t}, J=7.2 \mathrm{~Hz})$.

2,4-Dichloro-6-isopropoxy-1,3,5-triazine (13b) Cyanuric chloride $(1.85 \mathrm{~g}, 10.0 \mathrm{mmol})$ was added to a solution of sodium hydrogen carbonate $(858 \mathrm{mg}, 10.2 \mathrm{mmol}, 1.0 \mathrm{eq})$ in 2-propanol $(40 \mathrm{~mL})$ at room temperature. The mixture was stirred for $50 \mathrm{~min}$ at room temperature, then poured into water and extracted with ethyl acetate. The organic layer was washed with brine, dried over sodium sulfate and concentrated. The residue was purified by silica gel column chromatography (eluent: $n$-hexane-ethyl acetate 10:1) to afford $1.32 \mathrm{~g}(6.35 \mathrm{mmol}, 64 \%)$ of $\mathbf{1 3 b}$ as a colorless oil. ${ }^{1} \mathrm{H}-\mathrm{NMR}$ $\left(500 \mathrm{MHz}, \mathrm{CDCl}_{3}\right) \delta: 4.50(2 \mathrm{H}, \mathrm{t}, J=6.6 \mathrm{~Hz}), 5.47-5.37(1 \mathrm{H}$, m), $1.44(6 \mathrm{H}, \mathrm{d}, J=6.3 \mathrm{~Hz})$.

General Procedure for the Synthesis of Compounds 13c-13g Alcohol or phenol (1.0 eq) in chloroform $(5 \mathrm{~mL})$ and $N, N$-diisopropylethylamine (1 eq) in chloroform $(5 \mathrm{~mL})$ were added dropwise to a solution of cyanuric chloride ( $c a .2 .0 \mathrm{~g}$, $1.0 \mathrm{eq})$ in chloroform $(10 \mathrm{~mL})$ at $0^{\circ} \mathrm{C}$. The mixture was stirred for $20 \mathrm{~min}$ at $0^{\circ} \mathrm{C}$, then washed with dilute sodium hydroxide and brine, dried over sodium sulfate and concentrated. The residue was purified by silica gel column chromatography.

2-n-Butoxy-4,6-dichloro-1,3,5-triazine (13c)

Purification with silica gel column chromatography (eluent: $n$-hexane-ethyl acetate $10: 1)$ gave $13 \mathrm{c}(55 \%)$ as a clear oil. ${ }^{1} \mathrm{H}-\mathrm{NMR}\left(500 \mathrm{MHz}, \mathrm{CDCl}_{3}\right) \delta: 4.50(2 \mathrm{H}, \mathrm{t}, J=6.6 \mathrm{~Hz})$, $1.83-1.78(2 \mathrm{H}, \mathrm{m}), 1.49(2 \mathrm{H}, \mathrm{td}, J=7.6 \mathrm{~Hz}, 15.2 \mathrm{~Hz}), 0.98(3 \mathrm{H}$, $\mathrm{t}, J=7.4 \mathrm{~Hz}$ ).

\section{2,4-Dichloro-6-phenoxy-1,3,5-triazine (13d)}

Purification with silica gel column chromatography (eluent: $n$-hexane-ethyl acetate $10: 1)$ gave $\mathbf{1 3 d}(59 \%)$ as a white solid. ${ }^{1} \mathrm{H}-\mathrm{NMR}\left(500 \mathrm{MHz}, \mathrm{CDCl}_{3}\right) \delta: 7.47(2 \mathrm{H}, \mathrm{t}, J=8.0 \mathrm{~Hz}), 7.35$ $(1 \mathrm{H}, \mathrm{t}, J=7.4 \mathrm{~Hz}), 7.18(2 \mathrm{H}, \mathrm{d}, J=8.0 \mathrm{~Hz})$.

2,4-Dichloro-6-(2,2,2-trifluoroethoxy)-1,3,5-triazine (13e)

Purification with silica gel column chromatography (eluent: $n$-hexane-ethyl acetate $10: 1)$ gave 13 e $(64 \%)$ as a clear oil. ${ }^{1} \mathrm{H}-\mathrm{NMR}\left(500 \mathrm{MHz}, \mathrm{CDCl}_{3}\right) \delta: 4.88(2 \mathrm{H}, \mathrm{q}, J=7.8 \mathrm{~Hz})$.

2,4-Dichloro-6-(2-methoxylethoxy)-1,3,5-triazine (13f)

Purification with silica gel column chromatography (eluent: $n$-hexane-ethyl acetate $10: 1)$ gave $\mathbf{1 3 f}(34 \%)$ as a white solid. ${ }^{1} \mathrm{H}-\mathrm{NMR}\left(500 \mathrm{MHz}, \mathrm{CDCl}_{3}\right) \delta$ : 4.65-4.64 (2H, m), 3.77-3.75 $(2 \mathrm{H}, \mathrm{m}), 3.42(3 \mathrm{H}, \mathrm{s}), 7.35(1 \mathrm{H}, \mathrm{t}, J=7.4 \mathrm{~Hz}), 7.18(2 \mathrm{H}, \mathrm{d}$, $J=8.0 \mathrm{~Hz}$ ).

\section{2,4-Dichloro-6-(2-oxopropoxy)-1,3,5-triazine (13g)}

Purification with silica gel column chromatography (eluent: $n$-hexane-ethyl acetate $6: 4)$ gave $\mathbf{1 3 g}(58 \%)$ as ocher crystals. ${ }^{1} \mathrm{H}-\mathrm{NMR}\left(500 \mathrm{MHz}, \mathrm{CDCl}_{3}\right) \delta: 5.09(2 \mathrm{H}, \mathrm{s}), 2.27(3 \mathrm{H}, \mathrm{s})$.

General Procedure for the Synthesis of Compounds 14a-14g Phenol (1.0 eq) in dichloromethane $(5 \mathrm{~mL})$ and $N, N$ diisopropylethylamine (1 equiv) in dichloromethane $(5 \mathrm{~mL})$ were added dropwise to a solution of $13 \mathbf{a}-\mathbf{g}(\mathrm{ca} .700 \mathrm{mg}$, $1.0 \mathrm{eq})$ in dichloromethane $(10 \mathrm{~mL})$ at room temperature. The mixture was stirred for $30 \mathrm{~min}$ at room temperature. The reaction mixture was washed with dilute sodium hydroxide and brine, dried over sodium sulfate and concentrated. The residue was purified by silica gel column chromatography. 
2-Chloro-4-ethoxy-6-phenoxy-1,3,5-triazine (14a)

Purification by silica gel column chromatography (eluent: $n$ hexane-ethyl acetate $10: 1)$ gave $\mathbf{1 4 a}(84 \%)$ as colorless crystals. ${ }^{1} \mathrm{H}-\mathrm{NMR}\left(500 \mathrm{MHz}, \mathrm{CDCl}_{3}\right) \delta: 7.43(2 \mathrm{H}, \mathrm{tt}, J=2.3 \mathrm{~Hz}$, $8.0 \mathrm{~Hz}), 7.30(1 \mathrm{H}, \mathrm{t}, J=7.4 \mathrm{~Hz}), 7.17(2 \mathrm{H}, \mathrm{dt}, J=2.3 \mathrm{~Hz}$, $8.0 \mathrm{~Hz}), 4.44(2 \mathrm{H}, \mathrm{q}, J=5.9 \mathrm{~Hz}), 1.39(3 \mathrm{H}, \mathrm{t}, J=7.2 \mathrm{~Hz})$.

2-Chloro-4-(1-isopropoxy)-6-phenoxy-1,3,5-triazine (14b)

Purification by silica gel column chromatography (eluent: $n$-hexane-ethyl acetate $10: 1)$ gave $\mathbf{1 4 b}(70 \%)$ as a white solid. ${ }^{1} \mathrm{H}-\mathrm{NMR}\left(500 \mathrm{MHz}, \mathrm{CDCl}_{3}\right) \delta: 7.43(2 \mathrm{H}, \mathrm{t}, J=8.0 \mathrm{~Hz}), 7.29$ $(1 \mathrm{H}, \mathrm{t}, J=7.4 \mathrm{~Hz}), 7.17(2 \mathrm{H}, \mathrm{dq}, J=1.5,8.9 \mathrm{~Hz}), 5.26-5.19(1 \mathrm{H}$, m), $1.35(6 \mathrm{H}, \mathrm{d}, J=6.3 \mathrm{~Hz})$.

2-n-Butoxy-4-chloro-6-phenoxy-1,3,5-triazine (14c)

Purification by silica gel column chromatography (eluent: $n$ hexane-ethyl acetate $10: 1)$ gave $14 \mathrm{c}(66 \%)$ as colorless crystals. ${ }^{1} \mathrm{H}-\mathrm{NMR}\left(500 \mathrm{MHz}, \mathrm{CDCl}_{3}\right) \delta: 7.43(2 \mathrm{H}, \mathrm{t}, J=8.0 \mathrm{~Hz})$, $7.30(1 \mathrm{H}, \mathrm{t}, J=7.4 \mathrm{~Hz}), 7.17(2 \mathrm{H}, \mathrm{dq}, J=1.6 \mathrm{~Hz}, 8.7 \mathrm{~Hz}), 4.36$ $(2 \mathrm{H}, \mathrm{t}, J=6.6 \mathrm{~Hz}), 1.76-1.70(2 \mathrm{H}, \mathrm{m}), 1.45-1.39(2 \mathrm{H}, \mathrm{m}), 0.93$ $(3 \mathrm{H}, \mathrm{t}, J=7.4 \mathrm{~Hz})$.

2-Chloro-4,6-diphenoxy-1,3,5-triazine (14d)

Purification by silica gel column chromatography (eluent: $n$-hexane-ethyl acetate $5: 1)$ gave $\mathbf{1 4 d}(68 \%)$ as colorless crystals. ${ }^{1} \mathrm{H}-\mathrm{NMR}\left(500 \mathrm{MHz}, \mathrm{CDCl}_{3}\right) \delta: 7.40(4 \mathrm{H}, \mathrm{t}, J=8.0 \mathrm{~Hz})$, $7.28(2 \mathrm{H}, \mathrm{t}, J=7.4 \mathrm{~Hz}), 7.14(4 \mathrm{H}, \mathrm{td}, J=3.6 \mathrm{~Hz}, 5.3 \mathrm{~Hz})$.

2-Chloro-4-phenoxy-6-(2,2,2-trifluoroethoxy)-1,3,5-triazine (6e)

Purification by silica gel column chromatography (eluent: $n$ hexane-ethyl acetate $10: 1)$ gave $\mathbf{1 4 e}(70 \%)$ as colorless crystals. ${ }^{1} \mathrm{H}-\mathrm{NMR}\left(500 \mathrm{MHz}, \mathrm{CDCl}_{3}\right) \delta: 7.46(2 \mathrm{H}, \mathrm{t}, J=8.0 \mathrm{~Hz})$, $7.33(1 \mathrm{H}, \mathrm{t}, J=8.0 \mathrm{~Hz}), 7.17(2 \mathrm{H}, \mathrm{dq}, J=8.9 \mathrm{~Hz}, 1.7 \mathrm{~Hz}), 4.76$ $(2 \mathrm{H}, \mathrm{q}, J=8.0 \mathrm{~Hz})$.

2-Chloro-4-(2-methoxylethoxy)-6-phenoxy-1,3,5-triazine (14f)

Purification by silica gel column chromatography (eluent: $n$ hexane-ethyl acetate $5: 1)$ gave $\mathbf{1 4 f}(76 \%)$ as colorless crystals. ${ }^{1} \mathrm{H}-\mathrm{NMR}\left(500 \mathrm{MHz}, \mathrm{CDCl}_{3}\right) \delta: 7.43(2 \mathrm{H}, \mathrm{tt}, J=2.3 \mathrm{~Hz}, 8.0 \mathrm{~Hz})$, $7.29(1 \mathrm{H}, \mathrm{t}, J=7.4 \mathrm{~Hz}), 7.17(2 \mathrm{H}, \mathrm{dq}, J=1.6 \mathrm{~Hz}, 8.7 \mathrm{~Hz})$, 4.52-4.50 (2H, m), 3.70-3.68 (2H, m), 3.38 (3H, s).

2-Chloro-4-(2-oxopropoxy)-6-phenoxy-1,3,5-triazine (14g)

Purification by silica gel column chromatography (eluent: $n$-hexane-ethyl acetate $3: 1)$ gave $\mathbf{1 4 g}(62 \%)$ as a white solid. ${ }^{1} \mathrm{H}-\mathrm{NMR}\left(500 \mathrm{MHz}, \mathrm{CDCl}_{3}\right) \delta: 7.43(2 \mathrm{H}, \mathrm{t}, J=7.7 \mathrm{~Hz}), 7.30$ $(1 \mathrm{H}, \mathrm{t}, J=7.4 \mathrm{~Hz}), 7.14(2 \mathrm{H}, \mathrm{dd}, J=1.1 \mathrm{~Hz}, 8.6 \mathrm{~Hz}), 4.88(2 \mathrm{H}$, s), $2.08(3 \mathrm{H}, \mathrm{s})$.

General Procedure for the Synthesis of Compounds $\mathbf{1 5 a}-\mathbf{g}$ To a solution of $\mathbf{1 4 a}-\mathbf{g}(c a .250 \mathrm{mg}, 1.0 \mathrm{eq})$ in DMSO $(1.0 \mathrm{~mL})$ were added 4 -aminobenzonitrile $(2.0 \mathrm{eq})$ and $N, N$-diisopropylethylamine (1.0 eq) at room temperature. The mixture was stirred for $1 \mathrm{~h}$ at $100^{\circ} \mathrm{C}$, then cooled at room temperature, diluted with chloroform, washed with dilute hydrochloric acid and brine, dried over sodium sulfate, and concentrated. The residue was purified by silica gel column chromatography or recrystallization.

2-(4-Cyanoanilino)-4-ethoxy-6-phenoxy-1,3,5-triazine (15a)

Recrystallization from methanol gave 15a (35\%) as colorless crystals. mp $152.0-152.9^{\circ} \mathrm{C}$; ${ }^{1} \mathrm{H}-\mathrm{NMR}\left(500 \mathrm{MHz}, \mathrm{CDCl}_{3}\right)$ $\delta: 7.50(5 \mathrm{H}, \mathrm{br}), 7.45(2 \mathrm{H}, \mathrm{t}, J=8.0 \mathrm{~Hz}), 7.33(1 \mathrm{H}, \mathrm{t}, J=7.4 \mathrm{~Hz})$, $7.20(2 \mathrm{H}, \mathrm{d}, J=7.4 \mathrm{~Hz}), 4.45(2 \mathrm{H}, \mathrm{q}, J=7.1 \mathrm{~Hz}), 1.41(3 \mathrm{H}, \mathrm{t}$, $J=7.1 \mathrm{~Hz}$ ). HR-MS (ESI-TOF) $\mathrm{m} / \mathrm{z}: 332.1142\left([\mathrm{M}-\mathrm{H}]^{-}\right.$Calcd for $\mathrm{C}_{18} \mathrm{H}_{15} \mathrm{~N}_{5} \mathrm{O}_{2}$ 332.1138). Anal. Calcd for $\mathrm{C}_{18} \mathrm{H}_{12} \mathrm{~F}_{3} \mathrm{~N}_{5} \mathrm{O}_{2}$ : C, 64.86; H, 4.54; N, 21.01. Found: C, 64.82; H, 4.93; N, 20.82.
2-(4-Cyanoanilino)-4-(1-isopropoxy)-6-phenoxy-1,3,5triazine (15b)

Recrystallization from methanol gave $\mathbf{1 5 b}(60 \%)$ as colorless crystals. mp $182.8-184.6^{\circ} \mathrm{C}$; ${ }^{1} \mathrm{H}-\mathrm{NMR}\left(500 \mathrm{MHz}, \mathrm{CDCl}_{3}\right)$ $\delta$ : $7.59(2 \mathrm{H}, \mathrm{br}), 7.50(3 \mathrm{H}, \mathrm{br}), 7.45(2 \mathrm{H}, \mathrm{t}, J=8.0 \mathrm{~Hz}), 7.32$ $(1 \mathrm{H}, \mathrm{t}, J=7.4 \mathrm{~Hz}), 7.19(2 \mathrm{H}, \mathrm{d}, J=7.4 \mathrm{~Hz}), 5.32-5.24(2 \mathrm{H}, \mathrm{m})$, $1.38(6 \mathrm{H}, \mathrm{d}, J=6.3 \mathrm{~Hz}$ ). HR-MS (ESI-TOF) $m / z: 346.1300$ $\left([\mathrm{M}-\mathrm{H}]^{-}\right.$Calcd for $\mathrm{C}_{19} \mathrm{H}_{17} \mathrm{~N}_{5} \mathrm{O}_{2}$ 346.1299)). Anal. Calcd for $\mathrm{C}_{19} \mathrm{H}_{17} \mathrm{~N}_{5} \mathrm{O}_{2}$ : C, 65.69; H, 4.93; N, 20.16. Found: C, 65.65; H, $5.22 ; \mathrm{N}, 19.93$.

2-n-Butoxy-4-(4-cyanoanilino)-6-phenoxy-1,3,5-triazine (15c)

Recrystallization from methanol gave $\mathbf{1 5 c}(31 \%)$ as colorless crystals. mp $139.2-139.7^{\circ} \mathrm{C}$; ${ }^{1} \mathrm{H}-\mathrm{NMR}\left(500 \mathrm{MHz}, \mathrm{CDCl}_{3}\right) \delta$ : $7.50(5 \mathrm{H}, \mathrm{br}), 7.46(2 \mathrm{H}, \mathrm{t}, J=8.0 \mathrm{~Hz}), 7.33(1 \mathrm{H}, \mathrm{t}, J=7.4 \mathrm{~Hz})$, $7.20(2 \mathrm{H}, \mathrm{d}, J=7.4 \mathrm{~Hz}), 4.38(2 \mathrm{H}, \mathrm{t}, J=6.9 \mathrm{~Hz}), 1.80-1.74(2 \mathrm{H}$, m), $1.46(2 \mathrm{H}, \mathrm{m}), 0.96(3 \mathrm{H}, \mathrm{t}, J=7.4 \mathrm{~Hz})$. HR-MS (ESI-TOF) m/z: $360.1455\left([\mathrm{M}-\mathrm{H}]^{-}\right.$Calcd for $\mathrm{C}_{20} \mathrm{H}_{19} \mathrm{~N}_{5} \mathrm{O}_{2}$ 360.1471). Anal. Calcd for $\mathrm{C}_{20} \mathrm{H}_{19} \mathrm{~N}_{5} \mathrm{O}_{2}$ : C, 66.47; H, 5.30; N, 19.38. Found: C, 66.31; H, 5.61; N, 19.23.

2-(4-Cyanoanilino)-4,6-diphenoxy-1,3,5-triazine (15d)

Recrystallization from methanol gave $\mathbf{1 5 d}(23 \%)$ as colorless crystals. mp $204.8-205.9^{\circ} \mathrm{C} ;{ }^{1} \mathrm{H}-\mathrm{NMR}\left(500 \mathrm{MHz}, \mathrm{CDCl}_{3}\right)$ $\delta: 7.61(1 \mathrm{H}, \mathrm{s}), 7.44(4 \mathrm{H}, \mathrm{t}, J=7.7 \mathrm{~Hz}), 7.41(4 \mathrm{H}, \mathrm{s}), 7.32(2 \mathrm{H}$, br), $7.19(4 \mathrm{H}, \mathrm{d}, J=8.0 \mathrm{~Hz}$ ). HR-MS (ESI-TOF) $\mathrm{m} / \mathrm{z}: 380.1127$ $\left([\mathrm{M}-\mathrm{H}]^{-}\right.$Calcd for $\mathrm{C}_{22} \mathrm{H}_{15} \mathrm{~N}_{5} \mathrm{O}_{2}$ 380.1142). Anal. Calcd for $\mathrm{C}_{22} \mathrm{H}_{15} \mathrm{~N}_{5} \mathrm{O}_{2}$ : C, 69.28; H, 3.96; N, 18.36. Found: C, 69.45; H, $4.32 ; \mathrm{N}, 18.29$.

2-(4-Cyanoanilino)-4-phenoxy-6-(2,2,2-trifluoroethoxy)$1,3,5$-triazine $(\mathbf{1 5 e})$

Purification with silica gel column chromatography (eluent: $n$-hexane-ethyl acetate $5: 1)$ gave $\mathbf{1 5 e}(52 \%)$ as colorless crystals. mp $161.2-162.0^{\circ} \mathrm{C}$; ${ }^{1} \mathrm{H}-\mathrm{NMR}\left(500 \mathrm{MHz}, \mathrm{CDCl}_{3}\right) \delta$ : $7.61(1 \mathrm{H}, \mathrm{s}), 7.47(2 \mathrm{H}, \mathrm{t}, J=8.0 \mathrm{~Hz}), 7.46(4 \mathrm{H}, \mathrm{br}), 7.35(1 \mathrm{H}, \mathrm{t}$, $J=6.9 \mathrm{~Hz}), 7.19(2 \mathrm{H}, \mathrm{d}, J=8.0 \mathrm{~Hz}), 4.78(2 \mathrm{H}, \mathrm{q}, J=8.2 \mathrm{~Hz})$. HR-MS (ESI-TOF) $m / z: 386.0856 \quad\left([\mathrm{M}-\mathrm{H}]^{-}\right.$Calcd for $\mathrm{C}_{18} \mathrm{H}_{12} \mathrm{~F}_{3} \mathrm{~N}_{5} \mathrm{O}_{2}$ 386.0859). Anal. Calcd for $\mathrm{C}_{18} \mathrm{H}_{12} \mathrm{~F}_{3} \mathrm{~N}_{5} \mathrm{O}_{2}$ : C, 55.82; H, 3.12; N, 18.08. Found: C, 55.81; H, 3.50; N, 17.97.

2-(4-Cyanoanilino)-4-(2-methoxylethoxy)-6-phenoxy-1,3,5triazine (15f)

Purification with silica gel column chromatography (eluent: $n$-hexane-ethyl acetate $5: 1)$ gave $\mathbf{1 5 f}(88 \%)$ as colorless crystals. mp $145.8-147.2^{\circ} \mathrm{C}$; ${ }^{1} \mathrm{H}-\mathrm{NMR}\left(500 \mathrm{MHz}, \mathrm{CDCl}_{3}\right) \delta$ : $7.90(1 \mathrm{H}, \mathrm{br}), 7.49(4 \mathrm{H}, \mathrm{br}) .7 .45(2 \mathrm{H}, \mathrm{t}, J=7.7 \mathrm{~Hz}), 7.32(1 \mathrm{H}$, $\mathrm{t}, J=7.2 \mathrm{~Hz}), 7.18(2 \mathrm{H}, \mathrm{d}, J=7.4 \mathrm{~Hz}), 4.52(2 \mathrm{H}, \mathrm{t}, J=4.6 \mathrm{~Hz})$, $3.71(2 \mathrm{H}, \mathrm{t}, J=4.9 \mathrm{~Hz}) 3.40(3 \mathrm{H}, \mathrm{s})$. HR-MS (ESI-TOF) $\mathrm{m} / \mathrm{z}$ : $362.1244\left([\mathrm{M}-\mathrm{H}]^{-}\right.$Calcd for $\mathrm{C}_{19} \mathrm{H}_{17} \mathrm{~N}_{5} \mathrm{O}_{3}$ 362.1248). Anal. Calcd for $\mathrm{C}_{19} \mathrm{H}_{17} \mathrm{~N}_{5} \mathrm{O}_{3}$ : C, 62.80; H, 4.72; N, 19.27. Found: C, 62.97; H, 4.94; N, 19.24.

2-(4-Cyanoanilino)-4-(2-oxopropoxy)-6-phenoxy-1,3,5triazine (15g)

Purification with silica gel column chromatography (eluent: $n$-hexane-ethyl acetate $6: 4)$ gave $\mathbf{1 5 g}(27 \%)$ as colorless crystals. mp $145.8-147.2^{\circ} \mathrm{C}$; ${ }^{1} \mathrm{H}-\mathrm{NMR}\left(500 \mathrm{MHz}, \mathrm{CDCl}_{3}\right) \delta$ : $7.90(1 \mathrm{H}, \mathrm{br}), 7.49(4 \mathrm{H}, \mathrm{br}) .7 .45(2 \mathrm{H}, \mathrm{t}, J=7.7 \mathrm{~Hz}), 7.32(1 \mathrm{H}$, $\mathrm{t}, J=7.2 \mathrm{~Hz}), 7.18(2 \mathrm{H}, \mathrm{d}, J=7.4 \mathrm{~Hz}), 4.52(2 \mathrm{H}, \mathrm{t}, J=4.6 \mathrm{~Hz})$, $3.71(2 \mathrm{H}, \mathrm{t}, J=4.9 \mathrm{~Hz}) 3.40(3 \mathrm{H}, \mathrm{s})$. HR-MS (ESI-TOF) $\mathrm{m} / \mathrm{z}$ : $362.1244\left([\mathrm{M}-\mathrm{H}]^{-}\right.$Calcd for $\mathrm{C}_{19} \mathrm{H}_{17} \mathrm{~N}_{5} \mathrm{O}_{3}$ 362.1248). Anal. Calcd for $\mathrm{C}_{19} \mathrm{H}_{17} \mathrm{~N}_{5} \mathrm{O}_{3}$ : C, 62.80; H, 4.72; N, 19.27. Found: C, 62.97; H, 4.94; N, 19.24.

General Procedure for the Synthesis of Compounds 16a 
and 16b To a solution of 11d $(243 \mathrm{mg}, 1.00 \mathrm{mmol})$ in THF $(10 \mathrm{~mL})$ were added amine $(1.0 \mathrm{eq})$ and $N, N$-diisopropylethylamine $(1.0 \mathrm{eq})$ at room temperature. The mixture was stirred for $30 \mathrm{~min}$ at room temperature, then poured into water and extracted with ethyl acetate. The organic layer was washed with brine, dried over sodium sulfate and concentrated. The residue was purified by silica gel column chromatography (eluent: $n$-hexane-ethyl acetate $5: 1$ ).

2-Chloro-4-dimethylamino-6-phenoxy-1,3,5-triazine (16a)

Reaction of 11d with dimethylamine $40 \%$ in water gave 16a $(67 \%)$ as a white solid. ${ }^{1} \mathrm{H}-\mathrm{NMR}\left(500 \mathrm{MHz}, \mathrm{CDCl}_{3}\right) \delta$ : $7.39(2 \mathrm{H}, \mathrm{t}, J=7.7 \mathrm{~Hz}), 7.24(1 \mathrm{H}, \mathrm{t}, J=7.4 \mathrm{~Hz}), 7.17(2 \mathrm{H}, \mathrm{d}$, $J=7.4 \mathrm{~Hz}), 3.19(3 \mathrm{H}, \mathrm{s}), 3.03(3 \mathrm{H}, \mathrm{s})$.

2-Chloro-4-phenoxy-6-( $N$-pyrrolidinyl)-1,3,5-triazine (16b)

Reaction of 11d with pyrrolidine gave $\mathbf{1 7 b}(86 \%)$ as a white solid. ${ }^{1} \mathrm{H}-\mathrm{NMR}\left(500 \mathrm{MHz}, \mathrm{CDCl}_{3}\right) \delta$ : $7.39(2 \mathrm{H}, \mathrm{td}, J=1.7 \mathrm{~Hz}$, $7.7 \mathrm{~Hz}), 7.24(1 \mathrm{H}, \mathrm{t}, J=7.4 \mathrm{~Hz}), 7.18(2 \mathrm{H}, \mathrm{td}, J=4.3 \mathrm{~Hz}$, $2.1 \mathrm{~Hz}), 3.61(2 \mathrm{H}, \mathrm{t}, J=6.6 \mathrm{~Hz}), 3.44(2 \mathrm{H}, \mathrm{t}, J=6.6 \mathrm{~Hz})$, 1.99-1.90 (4H, m).

General Procedure for the Synthesis of Compounds 17a and $\mathbf{1 7 b}$ To a solution of $\mathbf{1 7} \mathbf{a}$ or $\mathbf{1 7 b}(c a .100 \mathrm{mg}, 1.0 \mathrm{eq})$ in DMSO $(500 \mu \mathrm{L})$ were added 4 -aminobenzonitrile (2.0 eq) and $N, N$-diisopropylethylamine $(2.0 \mathrm{eq})$ at room temperature. The mixture was stirred for $3 \mathrm{~h}$ at $160^{\circ} \mathrm{C}$, then cooled at room temperature, and diluted with chloroform. The whole was washed with dilute hydrochloric acid and brine, dried over sodium sulfate and concentrated. The residue was purified by recrystallization.

2-(4-Cyanoanilino)-4-dimethylamino-6-phenoxy-1,3,5triazine (17a)

Recrystallization from methanol gave 17a (33\%) as pale yellow crystals. mp $232.0-233.8^{\circ} \mathrm{C}$; ${ }^{1} \mathrm{H}-\mathrm{NMR} \quad(500 \mathrm{MHz}$, $\left.\mathrm{CDCl}_{3}\right) \delta: 7.59(2 \mathrm{H}, \mathrm{d}, J=7.4 \mathrm{~Hz}), 7.50(2 \mathrm{H}, \mathrm{d}, J=8.0 \mathrm{~Hz})$, $7.42(2 \mathrm{H}, \mathrm{td}, J=1.7 \mathrm{~Hz}, 7.0 \mathrm{~Hz}), 7.28(1 \mathrm{H}, \mathrm{t}, J=7.2 \mathrm{~Hz}), 7.20$ $(2 \mathrm{H}, \mathrm{td}, J=1.9 \mathrm{~Hz}, 3.7 \mathrm{~Hz}), 7.13(1 \mathrm{H}, \mathrm{s}), 3.20(3 \mathrm{H}, \mathrm{s}), 3.15$ $(3 \mathrm{H}, \mathrm{s})$. HR-MS (ESI-TOF) $\mathrm{m} / \mathrm{z}: 331.1297\left([\mathrm{M}-\mathrm{H}]^{-}\right.$Calcd for $\mathrm{C}_{18} \mathrm{H}_{16} \mathrm{~N}_{6} \mathrm{O}$ 331.1302). Anal. Calcd for $\mathrm{C}_{18} \mathrm{H}_{16} \mathrm{~N}_{6} \mathrm{O}: \mathrm{C}, 65.05 ; \mathrm{H}$, 4.85; N, 25.29. Found: C, 65.17; H, 5.16; N, 25.39.

2-(4-Cyanoanilino)-4-phenoxy-6-( $N$-pyrrolidinyl)-1,3,5triazine (17b)

Recrystallization from methanol gave $\mathbf{1 7 b}(44 \%)$ as brown crystals. mp $210.0-211.5^{\circ} \mathrm{C} ;{ }^{1} \mathrm{H}-\mathrm{NMR}\left(500 \mathrm{MHz}, \mathrm{CDCl}_{3}\right) \delta$ : $7.60(2 \mathrm{H}, \mathrm{br}), 7.48(2 \mathrm{H}, \mathrm{d}, J=8.0 \mathrm{~Hz}), 7.42(2 \mathrm{H}, \mathrm{t}, J=8.0 \mathrm{~Hz})$, $7.27(1 \mathrm{H}, \mathrm{t}, J=7.4 \mathrm{~Hz}), 7.20(3 \mathrm{H}, \mathrm{d}, J=7.4 \mathrm{~Hz}), 3.62(2 \mathrm{H}, \mathrm{t}$, $J=6.6 \mathrm{~Hz}), 3.58(2 \mathrm{H}, \mathrm{t}, J=6.6 \mathrm{~Hz}), 2.06-1.90(4 \mathrm{H}, \mathrm{m}) . \mathrm{HR}-\mathrm{MS}$ (ESI-TOF) $m / z: 357.1464\left([\mathrm{M}-\mathrm{H}]^{-}\right.$Calcd for $\mathrm{C}_{20} \mathrm{H}_{18} \mathrm{~N}_{6} \mathrm{O}$ 357.1458). Anal. Calcd for $\mathrm{C}_{20} \mathrm{H}_{18} \mathrm{~N}_{6} \mathrm{O}: \mathrm{C}, 67.02 ; \mathrm{H}, 5.09 ; \mathrm{N}$, 23.45. Found: C, 67.16; H, 5.35; N, 23.28.

\section{Biology}

T47D Alkaline Phosphate Assay T47D human breastcarcinoma cells were cultured in RPMI 1640 medium containing $10 \%(\mathrm{v} / \mathrm{v})$ fetal bovine serum (FBS), penicillin and streptomycin mixture at $37^{\circ} \mathrm{C}$ in a humidified atmosphere of $5 \% \mathrm{CO}_{2}$ in air. Cells were plated in 96 -well plates at $1 \times 10^{5}$ cells/well and incubated for $24 \mathrm{~h}\left(37^{\circ} \mathrm{C}, 5 \% \mathrm{CO}_{2}\right)$. The next day, the cells were treated with fresh media containing either DMSO or test compound plus progesterone $(0.1 \mathrm{nM})$, and incubated for $24 \mathrm{~h}$. The medium was aspirated and the cells were fixed with $100 \mu \mathrm{L}$ of $1.8 \%$ formalin (in phosphate buffered saline (PBS)). The fixed cells were washed with PBS and $75 \mu \mathrm{L}$ of assay buffer $[1 \mathrm{mg} / \mathrm{mL} p$-nitrophenyl phosphate (Thermo, U.S.A.) in diethanolamine aqueous solution, $\mathrm{pH}$ 9.0, $2 \mathrm{mM} \mathrm{MgCl}_{2}$ ] was added. Following incubation at $37^{\circ} \mathrm{C}$ with shielding from light for $3 \mathrm{~h}$, the reaction was terminated by the addition of $100 \mu \mathrm{L}$ of $1 \mathrm{~mol} / \mathrm{L} \mathrm{NaOH}$. The absorbance at $405 \mathrm{~nm}$ was measured with a Wallac 1420 multilabel counter (ParkinElmer Life Sciences, U.S.A.). All data points were measured in triplicate.

PR Binding Assay PR-binding experiments were performed as reported, using recombinant hPR-LBD purchased from Invitrogen. hPR-LBD was diluted with buffer $(20 \mathrm{mM}$ Tris- $\mathrm{HCl}, 300 \mathrm{mM} \mathrm{NaCl}, 1 \mathrm{mM}$ ethylenediaminetetraacetic acid (EDTA), $5 \mathrm{mM}$ dithiothreitol (DTT), $\mathrm{pH} 8.0$ ) to $5 \mathrm{nM}$ and $300 \mu \mathrm{L}$ aliquots were incubated in the dark at $4^{\circ} \mathrm{C}$ with $4 \mathrm{nM}$ $\left[1,2,6,7-{ }^{3} \mathrm{H}\right]$ progesterone (PerkinElmer, Inc.) and reference or test compounds (dissolved in DMSO; final concentration of DMSO was 3\%). Nonspecific binding was assessed by addition of a 200 -fold excess of nonradioactive progesterone. After $24 \mathrm{~h}, 30 \mu \mathrm{L}$ of Dextran T-70/ $\gamma$-globulin-coated charcoal suspension was added to the ligand/protein mixtures $(1 \%$ activated charcoal, $0.05 \% \gamma$-globulin, $0.05 \%$ Dextran 70 , final concentrations) and incubated at $4{ }^{\circ} \mathrm{C}$ for $5 \mathrm{~min}$. The charcoal was removed by centrifugation for $5 \mathrm{~min}$ at $1300 \times \boldsymbol{g}$, and the radioactivity of the supernatant was measured in Ultima Gold scintillation cocktail (PerkinElmer, Inc.) by using a liquid scintillation counter. All experiments were performed in duplicate.

Docking Simulation The structure of the LBD of hPR was prepared from the Protein Data Bank accession 2W8Y. Polar hydrogens were added, and partial atomic charges were assigned using AutoDockTools (ADT). Molecular docking was performed using AutoDock 4.2 with the Genetic Algorithm.

Acknowledgments This work was partially supported by the Japan Society for the Promotion of Science (JSPS) Grantsin-Aid for Scientific Research No. 17 H03887 (S.F.), as well as by the JSPS Core-to-Core Program, A. Advanced Research Networks, and Platform Project for Supporting in Drug Discovery and Life Science Research (Platform for Drug Discovery, Informatics, and Structural Life Science) from Japan Agency for Medical Research and Development (AMED).

Conflict of Interest The authors declare no conflict of interest.

\section{References}

1) Mangelsdorf D. J., Thummel C., Beato M., Herrlich P., Schüetz G., Umesono K., Blumberg B., Kastner P., Mark M., Chambon P., Evans R. M., Cell, 83, 835-839 (1995)

2) Zhang Z., Funk C., Glasser S. R., Mulholland J., Endocrinology, 135, 1256-1263 (1994)

3) Aupperlee M. D., Smith K. T., Kariagina A., Haslam S. Z., Endocrinology, 146, 3577-3588 (2005).

4) Rudolph L. M., Cornil C. A., Mittelman-Smith M. A., Rainville J. R., Remage-Healey L., Sinchak K., Micevych P. E., J. Neurosci., 36, $11449-11458$ (2016).

5) Guennoun R., Labombarda F., Gonzalez Deniselle M. C., Liere P., De Nicola A. F., Schumacher M., J. Steroid Biochem. Mol. Biol. 146, 48-61 (2015).

6) Melcangi R. C., Giatti S., Calabrese D., Pesaresi M., Cermenati G., Mitro N., Viviani B., Garcia-Segura L. M., Caruso D., Prog. Neurobiol., 113, 56-69 (2014).

7) Edgren R. A., Sturtevant F. M., Am. J. Obstet. Gynecol., 125, 1029- 
1038 (1976).

8) Vercellini P., De Giorgi O., Oldani S., Cortesi I., Panazza S., Crosignani P. G., Am. J. Obstet. Gynecol., 175, 396-401 (1996).

9) Torgerson D. J., Bell-Syer S. E., JAMA, 285, 2891-2897 (2001).

10) Zhang P., Terefenko E. A., Fensome A., Wrobel J., Winneker R., Zhang Z., Bioorg. Med. Chem. Lett., 13, 1313-1316 (2003).

11) Fensome A., Bender R., Chopra R., Cohen J., Collins M. A., Hudak V., Malakian K., Lockhead S., Olland A., Svenson K., Terefenko E. A., Unwalla R. J., Wilhelm J. M., Wolfrom S., Zhu Y., Zhang Z., Zhang P., Winneker R. C., Wrobel J., J. Med. Chem., 48, 5092-5095 (2005).

12) Brisken C., Nat. Rev. Cancer, 13, 385-396 (2013).

13) Diep C. H., Daniel A. R., Mauro L. J., Knutson T. P., Lange C. A., J. Mol. Endocrinol., 54, R31-R53 (2015).

14) Singh S. S., Belland L., Leyland N., von Riedemann S., Murji A., Am. J. Obstet. Gynecol., 218, 563-572.e1 (2018).

15) Kim J. J., Kurita T., Bulun S. E., Endocr. Rev., 34, 130-162 (2013).

16) Sun Y., Fang M., Davies H., Hu Z., Gynecol. Endocrinol., 30, 169-173 (2014).

17) Zhang P., Terefenko E. A., Fensome A., Wrobel J., Winneker R., Lundeen S., Marschke K. B., Zhang Z., J. Med. Chem., 45, 43794382 (2002).

18) Fensome A., Adams W. R., Adams A. L., Berrodin T. J., Cohen J., Huselton C., Illenberger A., Kern J. C., Hudak V. A., Marella M. A., Melenski E. G., McComas C. C., Mugford C. A., Slayden O. D., Yudt M., Zhang Z., Zhang P., Zhu Y., Winneker R. C., Wrobel J. E., J. Med. Chem., 51, 1861-1873 (2008).

19) Sakai H., Hirano T., Mori S., Fujii S., Masuno H., Kinoshita M., Kagechika H., Tanatani A., J. Med. Chem., 54, 7055-7065 (2011).

20) Richardson T. I., Clarke C., Yu K.-L., Yee Y. K., Bleisch T. J., Lopez J. E., Jones S., Hughes N. E., Muehl B. S., Lugar C. W., Moore T. L., Shetler P. K., Zink R. W., Osborne J. J., Montrose-
Rafizadeh C., Patel N., Geiser A. G., Galvin R. J., Dodge J. A., Acs. Med. Chem. Lett., 2, 148-153 (2011).

21) Yamada A., Kazui Y., Yoshioka H., Tanatani A., Mori S., Kagechika H., Fujii S., Acs. Med. Chem. Lett., 7, 1028-1033 (2016).

22) Nishiyama Y., Mori S., Makishima M., Fujii S., Kagechika H. Hashimoto Y., Ishikawa M., Acs. Med. Chem. Lett., 9, 641-645 (2018).

23) Fujii S., Yamada A., Nakano E., Takeuchi Y., Mori S., Masuno H., Kagechika H., Eur. J. Med. Chem., 84, 264-277 (2014).

24) Fujii S., Nakano E., Yanagida N., Mori S., Masuno H., Kagechika H., Bioorg. Med. Chem., 22, 5329-5337 (2014).

25) Koonin E. V., Wolf Y. I., Karev G. P., Nature (London), 420, 218 223 (2002).

26) Koch M. A., Wittenberg L.-O., Basu S., Jeyaraj D. A., Gourzoulidou E., Reinecke K., Odermatt A., Waldmann H., Proc. Natl. Acad. Sci. U.S.A., 101, 16721-16726 (2004).

27) Noguchi-Yachide T., Aoyama A., Makishima M., Miyachi H., Hashimoto Y., Bioorg. Med. Chem. Lett., 17, 3957-3961 (2007).

28) Hosoda S., Tanatani A., Wakabayashi K., Makishima M., Imai K., Miyachi H., Nagasawa K., Hashimoto Y., Bioorg. Med. Chem., 14, 5489-5502 (2006).

29) Kaitoh K., Toyama H., Hashimoto Y., Fujii S., Heterocycles, 95, 547-556 (2017)

30) Gronemeyer H., Gustafsson J. A., Laudet V., Nat. Rev. Drug Discov., 3, 950-964 (2004).

31) Di Lorenzo D., Albertini A., Zava D., Cancer Res., 51, 4470-4475 (1991).

32) Raaijmakers H. C. A., Versteegh J. E., Uitdehaag J. C. M., J. Biol. Chem., 284, 19572-19579 (2009).

33) Morris G. M., Huey R., Lindstrom W., Sanner M. F., Belew R. K., Goodsell D. S., Olson A. J., J. Comput. Chem., 30, 2785-2791 (2009). 